NBER WORKING PAPER SERIES

\title{
CAN POLICY AFFECT INITIATION OF ADDICTIVE SUBSTANCE USE? EVIDENCE FROM OPIOID PRESCRIBING
}

\author{
Daniel W. Sacks \\ Alex Hollingsworth \\ Thuy D. Nguyen \\ Kosali I. Simon \\ Working Paper 25974 \\ http://www.nber.org/papers/w25974 \\ NATIONAL BUREAU OF ECONOMIC RESEARCH \\ 1050 Massachusetts Avenue \\ Cambridge, MA 02138 \\ June 2019
}

We are grateful to Dhaval Dave, Catherine Maclean, Justine Mallatt, and audiences at University of Georgia, University of Illinois, Indiana University and the Midwest Health Economics Conference for helpful comments. This research was supported in part by National Institute on Drug Abuse, R01 DA039928 (PI Brea Perry), "Doctor shopping for controlled substances: Insights from two-mode social network analysis," and the Indiana University Addictions Grand Challenge Initiative. We acknowledge the Indiana University Pervasive Technology Institute for providing HPC resources that have contributed to the research results reported in this paper (https://pti.iu.edu). The views expressed herein are those of the authors and do not necessarily reflect the views of the National Bureau of Economic Research.

NBER working papers are circulated for discussion and comment purposes. They have not been peer-reviewed or been subject to the review by the NBER Board of Directors that accompanies official NBER publications.

(C) 2019 by Daniel W. Sacks, Alex Hollingsworth, Thuy D. Nguyen, and Kosali I. Simon. All rights reserved. Short sections of text, not to exceed two paragraphs, may be quoted without explicit permission provided that full credit, including $\odot$ notice, is given to the source. 
Can Policy Affect Initiation of Addictive Substance Use? Evidence from Opioid Prescribing Daniel W. Sacks, Alex Hollingsworth, Thuy D. Nguyen, and Kosali I. Simon

NBER Working Paper No. 25974

June 2019

JEL No. I12,I18

\begin{abstract}
$\underline{\text { ABSTRACT }}$
Drug control policy can have unintended consequences by pushing existing users to alternative, possibly more dangerous substances. Policies that target only new users may therefore be especially promising. Using commercial insurance claims data, we provide the first evidence on a set of new policies intended to reduce opioid initiation in the form of limits on initial prescription length. We also provide the first evidence on the impact of must-access prescription drug monitoring programs (MA-PDMPs), laws that do not target new users, on initial opioid use. Although initial limit policies reduce the average length of initial prescriptions, they do so primarily by raising the frequency of short prescriptions, resulting in increases in opioids dispensed to new users. In contrast, we find that MA-PDMPs reduce opioids dispensed to new users, even though they do not explicitly set out to do so. Neither policy significantly affects extreme use such as doctor shopping among new patients, because such behavior is very rare.
\end{abstract}

Daniel W. Sacks

Kelly School of Business

Indiana University

1309 E. 10th Street

Bloomington, IN 47405

dansacks@indiana.edu

Alex Hollingsworth

O'Neill School of Public and

Environmental Affairs

Indiana University

Rm 329

1315 E. Tenth St.

Bloomington, IN 47405

hollinal@indiana.edu
Thuy D. Nguyen

O'Neill School of Public

and Environmental Affairs

Indiana University

Bloomington, IN 47401

thdnguye@indiana.edu

Kosali I. Simon

O'Neill School of Public

and Environmental Affairs

Indiana University

$\mathrm{Rm} 443$

1315 East Tenth Street

Bloomington, IN 47405-1701

and NBER

simonkos@indiana.edu 


\section{Introduction}

Policymakers have a longstanding interest in regulating the use of potentially addictive substances. The use of many drugs is illegal, often through outright prohibition or through age restrictions, as in the case of alcohol and tobacco. Even when legal many substances are heavily taxed, in part to discourage use. Moreover, potentially addictive drugs are often formulated in such a way as to discourage abuse. For example, the long-acting opioid Oxycontin was reformulated in 2010 so that it could not be crushed and snorted to deliver an immediate, potent dose. Although such policies may deter drug and alcohol use, they have potentially harmful unintended consequences. Taxing cigarettes encourages substitution towards higher nicotine-content products (e.g. Evans and Farrelly (1998); Cotti et al. (2016)). When Oxycontin was reformulated, both its use and misuse fell, but many users substituted towards heroin, and opioid-related overdoses skyrocketed (Alpert et al., 2018; Evans et al., 2019). Harmful consequences arise because these policies not only deter new users, but they also target inframarginal users, who, if they are undeterred, end up either bearing higher costs or substituting to more dangerous substances. In this paper, we ask whether substance use policies can deter new users without causing harmful compensatory behavior.

We study the regulation of addictive substances among new users in the context of prescription opioids. Opioid use and misuse are major public health concerns, as reflected in the high and rising number of opioid-related deaths. Opioids were involved in roughly 47,500 deaths in $2017-1.7 \%$ of the national total, an increase of $9.6 \%$ since 2016 and over 300\% since 1999 (Scholl et al. 2019, Ruhm, 2018). Rising mortality, combined with widespread use and misuse of prescription and illegal opioids, has been labelled an opioid crisis. Policy responses to this crisis have entailed attempts to thwart prescription drug misuse, mitigate harm, and improve access to treatment. Most state policies have been ineffective in reducing opioid prescribing (Meara et al. 2016). An exception is must-access prescription drug monitoring programs (MA-PDMPs), which require prescribers to check state databases of controlled substance prescribing before writing an opioid prescription. These laws reduce opioid use and, especially, tail outcomes such as 
doctor shopping (filling prescriptions from several doctors) and extremely high levels of use (Buchmueller and Carey, 2018). However, they may unintentionally increase crime and illicit drug use (Mallatt, 2017; Dave et al., 2018).

In this paper we focus on a set of recently-enacted policies specifically designed to prevent new users from becoming addicted to opioids. These are laws that limit the strength and length of opioid prescriptions for new users with acute, non-cancer pain. Only two states had such laws prior to 2011, but by the end of 2018, 26 states had passed initial prescription limits. The typical law limits an initial prescription for acute pain to seven days supply; prior to such laws, it was possible to write a prescription for 31 days or longer (Davis et al., 2019). Policymakers had two specific motivations in passing these laws. First, they hoped to limit unintentional addiction among new patients, who diligently take their prescription, not appreciating the risks of developing opioid addiction. For example, former Ohio Governor John Kasich, stated that "by setting aggressive prescription limits, we're taking big steps to prevent opiate addition from happening in the first place" (Kasich, 2017). Consistent with this concern, observational evidence indicates that the probability of becoming a chronic opioid user rises sharply in the length of the initial prescription (Shah et al., 2017). Second, large initial prescriptions create a stock of drugs available for diversion to non-prescribed users. Not all patients consume the entire prescription and policymakers hoped to reduce diversion possibilities by reducing the number of leftover opiates. Diversion of prescriptions is considered the source of drugs for a large fraction of current misusers (Lipsari and Hughes, 2017), and prior research shows state policies may reduce diversion (Surratt et al., 2014). Research to date has neither examined the effectiveness of initial prescription limits laws, nor considered how policies in general affect opioid initiation.

We evaluate whether state opioid policy can influence initial prescriptions, including both the hazard and intensity of new use. We estimate difference-in-differences models using health insurance claims data from a national commercial insurer. As our focus is new use, our sample is restricted to cancer-free, initially "opioid-naïve" patients who had not filled an opioid prescription in at least the prior 12 months. This focus on new users is novel to the literature and there are at least two reasons to care about this group. 
While harm reduction among all existing users is important, reducing initiation is the most promising avenue to improving opioid use disorders in the longer run. Second, to the extent that opioids are addictive, it may be much harder to discourage existing users than to prevent new use, and efforts to discourage existing users may be more likely to induce substitution towards more dangerous illicit drug use.

Our claims data, which begin in 2007 and run through March of 2018, offer several advantages over previously used data to study opioid use and prescribing. Much of the prior research that has examined the effect of state laws has used state-level aggregate data on dispensed totals derived from DEA records or from Medicaid. It is not possible to study new users with these data, making it difficult to examine laws targeting initial prescriptions. Recent research has also used individual level Medicare claims data. Opioid use is common among Medicare beneficiaries, but those data give an incomplete picture of opioid use in the United States. Moreover, Medicare data are available generally with a 2-3 year lag, which makes it hard to study effects of state initial prescription limit laws.

We begin by describing the characteristics of new opioid use. Every month, about 1 percent of people with no prior opioid use fill an opioid prescription. Our first finding is that initial prescriptions are fairly short, only 6.4 days on average. Even in states without a limit on initial prescription length, 80 percent of initial prescriptions last for 7 days or fewer, and 91 percent are for 14 days or fewer; this is true even in the earliest years of our data.1 As the modal law limits initial prescriptions for acute pain to 7 days or fewer, there is therefore little scope for these laws to bite. Some laws impose tighter limits; however, we find that even in states with 3-5 day limits, initial prescriptions are often for longer than the statutory amount.

Our second finding is that, nonetheless, these laws work to reduce the length of the initial prescription. Initial limit policies reduce the probability of an initial prescription exceeding 7 days by 20 percent, and overall the laws reduce the average length of the initial prescription by about half a day. However, rather than reduce initial prescription length by reducing the frequency of long prescriptions, initial limit policies in fact in${ }_{1}^{1}$ Shah et al. (2017) similarly find that 70 percent of initial prescriptions are for 7 days or fewer. 
crease the frequency of short prescriptions; in particular, we find that the laws induce physicians to write more prescriptions for 1-7 days. Although the laws also generate a reduction in long prescriptions, the net effect is a 4 percent increase in the hazard of new prescriptions, as well as a 6 percent increase in the total amount of opioids dispensed to new patients. These results suggest that initial prescription limits are ineffective in reducing opioids dispensed to new users. One possible mechanism for these surprising results is that physicians could interpret the initial prescription limits as signalling the safety or acceptability of short prescriptions.

While limits on initial prescriptions appear ineffective at reducing mean opioid consumption among new users, they could still reduce low-probability events such as dangerous levels of consumption or doctor shopping. We find no evidence to support this view. Limits on initial prescriptions are not associated with reductions in the probability of having high days supply, high daily dose, overlapping claims, or doctor shopping in the initial spell. We caution, however, that such extreme events may take many months or years to develop from the initial prescription, and these laws may be too recently passed to detect effects on these outcomes. Overall, our evidence suggests that initial prescription limits have not been effective in their goal of reducing opioids dispensed in the initial spell.

Although initial prescription limits appear ineffective at reducing new opioid use, other state prescribing policies may be more effective. We find that MA-PDMPs deter new use, decreasing the hazard of initial prescriptions by about 3 percent. However, like initial limit policies, they have no impact on markers of dangerous use among new enrollees in the short run. These finding are novel to the literature, which has not considered the impact of MA-PDMPS on new use. ${ }^{2}$ Overall, our findings suggest that initial prescription limits may not be particularly effective for reducing new use, but that MA-PDMPs may be even more effective than previously thought, as they reduce both new as well as extreme use.

$\sqrt{2}$ Kilby (2015) estimates the impact of MA-PDMPs on new opioid use, but does not consider MA-PDMPs in particular. She finds quantitatively small effects, about 40 percent of our estimate, which is consistent with the evidence in Buchmueller and Carey (2018) that non-must-access PDMPs have limited impacts on opioid use. 


\section{Background}

\subsection{Opioid prescribing in the United States}

The focus of our study is opioid analgesics, which are prescription painkillers. Prior to the 1990s, opioids were prescribed relatively rarely, because physicians were concerned about addiction, and downplayed pain management. Prescribing increased in the 1990s, when the medical community began to define pain as the "fifth vital sign" and increasingly acknowledged the historic under-treatment of pain (Merboth and Barnason, 2000; Mularski et al. 2006: Tompkins et al., 2017). Simultaneously, Oxycontin-a high dose, extended release opioid-was launched for use in the U.S. in 1996 and was subsequently heavily marketed as having a lower potential for abuse than existing (short-acting) opioids (Van Zee, 2009).

These two changes in the culture of pain management were followed by a rapid increase in both opioid prescriptions and opioid-related mortality in the United States. In the recent past, the United States has prescribed an exceptional amount of opioids. For example, from 2007 to 2009 Americans consumed about 15 doses of opioids per person per year, twice as many opioids per capita as did the second ranking nation, Canada, and 7.5 times as many as the average European country (International Narcotics Control Board, 2010). Opioid prescribing in the United States has declined about 10 percent from its 2010 peak, but remains extremely high relative to other countries (Centers for Disease Control and Prevention, 2018).

This high rate of opioid prescribing has alarmed policy makers and public health officials. It raises the possibility that individuals will develop dependence disorder, and that a large volume of opioids may be diverted, i.e. consumed by those without a valid prescription; indeed, 10.7 million people misused prescription pain killers in 2013-2014 (Lipsari and Hughes, 2017). The rise in opioid use is particularly alarming as it has been accompanied by a dramatic rise in opioid related mortality. Deaths from natural and semi-synthetic opioids (including prescription opioids) roughly quadrupled between 2000 and 2016, and deaths from heroin and synthetic opioids (such as fentanyl, which is dramatically stronger than heroin) have grown even more rapidly (Hedegaard et al., 2017, 
Ruhm, 2018). The increase in opioid-related mortality has been so large that it has led to an increase in overall mortality rates for some cohorts of non-Hispanic white Americans (Case and Deaton, 2015: Kochanek et al., 2016).

High opioid use could increase opioid-related mortality through several channels. First, prescription opioids are potentially addictive, meaning that patients develop tolerance, requiring ever stronger and closer to fatal doses to manage their pain. (White and Irvine, 1999). Second, even at low levels, opioids can be dangerous when taken in combination with benzodiazepines (e.g. Xanax), a commonly prescribed class of sedatives (White and Irvine, 1999: Jones et al., 2012). Benzodiazepines were involved in 3 percent of opioid-analgesic-related overdoses in 2011 (Chen et al., 2014). Third, for some, prescription opioids act as a gateway to stronger and more dangerous drugs such as heroin and fentanyl, which carry a higher risk of overdose, as has been observed with Oxycontin's reformulation (Alpert et al., 2018; Evans et al., 2019).

\subsection{Policy responses}

There have been several dimensions of U.S. policy responses to limit opioid prescribing and use. Our focus is on limits on initial prescriptions for acute pain and on MAPDMPs, two sets of recently enacted laws that we describe in more detail below. Other policy responses include features designed to either reduce access or reduce harm associated with use. Examples of such policies include abuse-deterrent reformulation, and rescheduling of low-strength opioids to make them harder to obtain and refill. There are also a host of state-specific policies that in earlier times, Meara et al. (2016) find to be largely ineffective in reducing opioid prescribing. In addition to state-specific policies, the CDC issued prescribing guidelines in July 2016, urging prescribers to avoid writing long and strong opioid prescriptions (Dowell et al. 2016). Some insurers have also responded by limiting opioid access, for example with prior authorization requirements (Dillender, 2018), as have some individual health care systems. $\mathrm{3}^{3}$

Initial prescription limits In the last few years, many states have enacted laws that

3-See, for example, https://www.wfyi.org/news/articles/how-one-hospital-drasticallycut-opioid-prescriptions. 
Figure 1: Initial prescription limits and MA-PDMPs in effect, by year
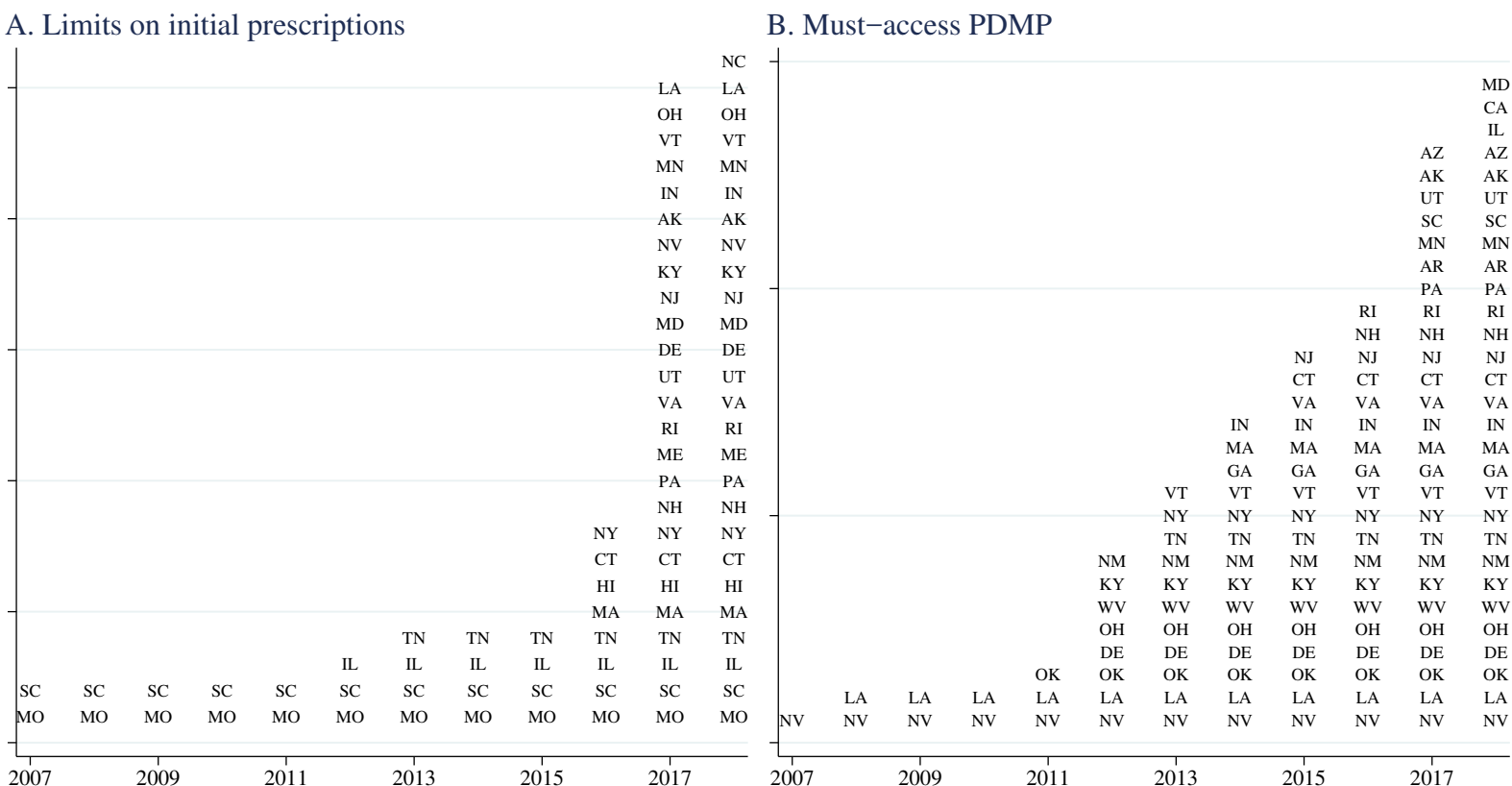

Notes: For each year of our data, we report in Panel A the set of states with limits on the initial prescription in effect, and in Panel B the set of states with MA-PDMPs in effect. Source: Davis et al. (2019) for panel A; pdaps.org and http://www.namsdl.org/prescription-monitoring-programs.cfm for panel B.

limit initial prescriptions for acute pain among new opioid users. Davis et al. (2019) describe these laws in more detail and report on the dates of implementation. Panel A of Figure 1 1 reports which states have such limits in effect in each year, and Appendix Table A.1 provides further details. As of 2006, only Missouri had such a law (which was passed decades ago) and from 2007 to 2013 only three additional states enacted initial limits. In 2016 four more states passed initial limits, followed by 17 in 2017, and one in 2018. By the end of 2018, 26 states had some form of limits on initial opioid prescriptions for acute pain..$^{4}$

There are reasons to believe that limiting opioid prescriptions to patients will reduce

4 4hese initial prescription limits are not among the many opioid-control laws studied by Meara et al. (2016). They study different prescription restrictions as well as tamper resistant prescription forms, ID requirements, doctor shopping, physician exams, pharmacist verification, PDMPs, and pain clinics. Their prescription restrictions do not specifically apply to new prescriptions. As they note, only Iowa and Vermont imposed quantitative prescription limits during their analysis periods, which runs through 2013, whereas most of the laws we studied were passed in 2016 and beyond. 
the likelihood of problematic future opioid use. Using a small-sample survey of nonmedical opioid users, Butler et al. (2016) show how an initial medical opioid prescription affects the hazard of future non-medical use; reported median time from initial medical prescription to the first non-medical use was six months for misuse for non medical reasons, and 18 months for use to avoid withdrawal. Barnett et al. (2017) show that patients quasi-exogenously assigned to emergency department doctors with higher opioid prescribing rates are themselves more likely to get a high-strength opioid, and substantially more likely to engage in long-term opioid use than those assigned to low-prescribing physicians.

These laws are heterogeneous in several dimensions. All but one limits the days supply, with limits ranging from 3 days to 35 days. The most common limit, used in 13 states, is 7 days. In addition to restricting prescription length in days, eight states also limit the strength of the prescription, to a certain morphine-milligram equivalent per day (e.g. 30 or 90). Many of the laws-16-allow for exceptions based on professional judgment or for surgical pain. We show below that the statutory limits set by these laws do not always bind, particularly for states with very short (3-5 day) limits.

Policymakers appear to have two specific goals for these laws, beyond a general desire to reduce opioid addiction, overdose, and mortality. First, they hope to prevent unintentional addictions, which could happen if patients dutifully comply with a long prescription, not realizing the addictive potential of opioids. Second, they hope to reduce the supply of opioids available for diversion. Large initial prescriptions create the potential for diversion because not everyone consumes the entire prescription. Data from the 2015 National Survey of Drug Use and Health show that of those who reported misusing opioids, 60 percent did so without a valid prescription and 40 percent obtained the drugs at no cost from a relative or friend (Han et al., 2017). For both goals, a key question for these policies is whether they actually reduce the total volume of opioids dispensed to new users.

MA-PDMPS PDMPs are state-wide databases recording all prescriptions dispensed (within a certain class, such as schedule II-IV narcotics). PDMPs enable prescribers to better detect drug-seeking behavior (such as a patient with prescriptions from many differ- 
ent providers), as well as potentially dangerous co-prescribing (such as benzodiazepines with opioids). PDMPs are extremely common-every state but Missouri has one as of July 2016 - but not all states require prescribers to access the database before writing a prescription. Buchmueller and Carey (2018) argue that prescribers rarely access a PDMP unless they are required to do so, and they show that only MA-PDMPs have an effect on opioid use. We therefore focus on must-access provisions of PDMPs.

We code and date MA-PDMPs following the logic of Buchmueller and Carey (2018) as closely as possible; while their data go through mid-2012, we extend the coding of MA-PDMPs through 2018. We begin by using the database provided by pdaps . org, the same source as Buchmueller and Carey (2018). This database records whether each state has a PDMP, the date of PDMP implementation, and the rules around access to PDMP. As the database runs through July 2016, we obtain more recent coding from the National Alliance for Modal State Drug Laws (NAMSDL) $5^{5}$ NAMSDL coding is current for laws passed through January 2018, the last month of initial prescriptions we study. We define a MA-PDMP as a PDMP which requires at least some providers to access it in at least some circumstances, consistent with prior research $[$ Panel B of Figure 1 reports which states have MA-PDMPs in effect in each year, and Appendix Table A.1 provides further details. Thirty states have enacted MA-PDMP legislation by the end of our sample period; our data thus cover the 10 states enacting MA-PDMPs studied by Buchmueller and Carey (2018), as well as an additional 20 states subsequently enacting MA-PDMPs.

\section{Data and empirical strategy}

\subsection{Data}

We use a comprehensive database of commercial insurance claims from a large, national insurer, with both employer-sponsored plans and Affordable Care Act Exchange plans. Our database covers claims from January 2007 through April 2018. Every state is 5 http://www.namsdl.org/prescription-monitoring-programs.cfm

6 We make one exception, consistent with Buchmueller and Carey (2018). Until 2015, Vermont's PDMP required access only when a patient requested a replacement prescription for one that had been lost or destroyed. We code this as a non-must-access. 
represented in every month. For budgetary reasons we purchased a 20 percent random sample of all enrollees during this period, as well as a 100 percent sample of all patients who ever filled an opioid prescription.7 When studying new fill rates, we use the 20 percent sample; when studying characteristics of opioid use, we use the second sample, to maximize power.

To identify opioid fills, we merged in a database containing the National Drug Code for all prescription opioids (Prescription Drug Monitoring Program Training and Technical Assistance, 2013). This database also contains a conversion factor to put different opioids on a common scale, morphine-equivalent doses (MED), which converts units of a given opioid into milligrams of morphine. We measure the length of a prescription by its days supply, and the total amount of opioids prescribed as the "morphine-equivalent days" (MED), the product of days supply, morphine equivalent doses, and strength. The modal opioid in the claims data is 5-mg hydrocodone, which has an MME of 1 , so a prescription for 7 days supply would have an MED of 35.

Sample construction and initial spells Our analysis focuses on new users, which we define as enrollees who fill a prescription for an opioid after at least 12 months without any opioid fills, and who were continuously enrolled for at least 12 months at the time of the initial fill. We limit the sample to the continuously enrolled to avoid misclassifying new enrollees as new users. Our sample is also limited to enrollees with both prescription drug and medical coverage. Because we require a look-back period for defining new users, our analysis sample begins in January 2008. Finally, we exclude patient-years that have a cancer diagnoses, because the prescription limits we study do not apply to cancer patients.

We are interested in how MA-PDMPs and initial limit policies affect not only the initial prescription but also subsequent use. We therefore consider outcomes during the "initial spell," which we define as the initial prescription and any prescriptions filled during the subsequent 90 days. We look at the initial spell in addition to the initial prescription

7 We obtained all records over the time period January 2007- March 2018 for a randomly chosen 20 percent of enrollees who appeared at least once during this time period. Some individuals are present only for a subset of the time period, reflecting the churn in private insurance coverage, but our sample remains representative of privately insured enrollees and has a potentially long panel dimension. 
because we want to measure whether shorter initial prescriptions are offset by longer subsequent prescriptions. We focus on 90 days because our data run through April 2018, and the last limit on initial prescriptions in our data was passed in December 2017. Thus, 90 days allows us to study all law changes and still have two months of post-period data following each new law. To avoid censored outcomes, we further limit our sample to those who were continuously enrolled for at least three months beyond their initial prescription. Appendix Table A.2 shows how the sample size changes as we impose our selection criteria. The final denominator data consists of 6.9 million enrollees, and the final numerator data consists of 17.3 million enrollees with at least one prescription for a controlled substance.

We aggregate our data to state-month cells, and conduct all analyses at this level, weighting by the appropriate sample size. These cells give the average outcomes among enrollees whose new use begins in the given state-month. For example, the cell CaliforniaJanuary-2016 reflects the experiences between January and March of all enrollees in California who initiated use in January 2016, denominated by the number of opioid naive enrollees in California as of January 2016.

Outcomes We construct several outcomes related to the initial prescription and the initial spell. We start with measures of average use: days supply and days MED in the initial prescription and the initial spell, as well as number of fills in the initial spell. We obtain the spell-level outcomes by aggregating over all prescriptions filled within three months of the initial prescription. For example, if a patient's initial prescription was for seven days and she obtained an additional seven days supply prescription after eight days, we would say her initial spell had 14 days supply. If each prescription was for 10 mg hydrophone (with an MED of 1), we would say she had 70 days MED for her initial prescription and a daily MED of 1.56 for her initial spell $]^{8}$

We are interested not only in standard prescription outcomes but also in extreme events which may be indicative of dangerous use or abuse. To examine extreme out-

8 Note that we work with MED for the initial prescription but daily MED for the initial spell. The reason for this is that the days of the initial spell is fixed at 90, making it easy to define daily MED. But for the initial prescription, the denominator would be days supply, meaning that a lower daily MED could be due to a strong but short prescription. 
comes, we consider five definitions of potentially problematic opioid use during the initial (90 day) spell. The first is an indicator for greater than 90 days supply, meaning that on average over the initial spell, the patient had more than one days supply per day. Next, we define an indicator for greater than $120 \mathrm{MME}$ per day, another measure of potentially dangerous use. Third, we look at doctor shopping, defined as having prescriptions from three or more prescribers, a measure of drug-seeking behavior. Finally, we look at two measures of overlapping claims: overlapping opioid prescriptions (defined as one opioid prescription beginning at least 7 days before the prior one ends), and concurrent benzodiazepine use (defined as at least one day in which a patient has both benzodiazepine and opioid days supply). We include this last outcome because benzodiazepines and opioids are particularly dangerous when taken in combination (e.g. Dasgupta et al. (2016)). These measures largely parallel those in Buchmueller and Carey (2018), but they are less extreme, as appropriate for our focus on new users. For example, Buchmueller and Carey (2018) define doctor shopping as having prescriptions from five or more prescribers. We focus on less extreme outcomes because we find very few signs of potentially dangerous opioid use relative to their Medicare sample, and we have more power with the less extreme outcomes.

Summary statistics We report summary statistics for new spells in Table 1. Our sample consists of about 10.3 million new spells. The hazard of new spell initiation is just over 0.01 , meaning roughly one percent of previous non-users initiate use in a given month. The modal prescription is written by a physician. Primary care providers write about 20 percent of all prescriptions, while pain specialist-written prescriptions are rare (at least among new users). Dentists prescribe 14 percent of initial prescriptions, and nurse practitioners and physicians' assistants collectively prescribe less than 10 percent.

The average initial prescription is for slightly less than one week, which foreshadows the limited scope for these laws to affect the modal existing prescription. About a quarter of initial spells involve more than one fill. Looking across all fills in the initial spell, total days supply averages 10.9. This demonstrates the importance of considering a period beyond the initial prescription; as looking just at the initial prescription, misses 40 percent of use in the first three months. The average days MED is about 114, roughly equivalent 
Table 1: Summary statistics on new spells

\begin{tabular}{|c|c|c|c|}
\hline A. Extensive margin & Hazard rate & & \\
\hline New fill & 0.011 & & \\
\hline B. Initial prescription characteristics & Mean & Median & 90th percentile \\
\hline Days supply & 6.38 & 4 & 12 \\
\hline Days MED & 49.83 & 25 & 90 \\
\hline Pills per days supply & 6.52 & 6 & 10 \\
\hline Long acting & 0.01 & & \\
\hline \multicolumn{4}{|l|}{ Prescriber type ... } \\
\hline Physician & 0.57 & & \\
\hline Primary care provider & 0.20 & & \\
\hline Surgeon & 0.13 & & \\
\hline Pain specialist & 0.002 & & \\
\hline Dentist & 0.14 & & \\
\hline Nurse practitioner & 0.03 & & \\
\hline Physicians' assistant & 0.05 & & \\
\hline Unknown & 0.18 & & \\
\hline C. Spell characteristics & Mean & Median & 90th percentile \\
\hline Days supply & 10.90 & 5 & 26 \\
\hline Daily MED & 114 & 30 & 160 \\
\hline Number of fills & 1.47 & 1 & 3 \\
\hline Greater than 1 fill & 0.27 & & \\
\hline Number of prescribers & 1.18 & 1 & 2 \\
\hline C. Dangerous use indicators & Mean & & \\
\hline$\geq 90$ days supplied & 0.014 & & \\
\hline$\geq 120$ daily MED & 0.001 & & \\
\hline$\geq 3$ prescribers & 0.027 & & \\
\hline Overlapping opioid claims & 0.033 & & \\
\hline Concurrent benzodiazepine & 0.071 & & \\
\hline Count of new spells & $10,292,576$ & & \\
\hline
\end{tabular}

Table reports summary statistics for new spells. Sample is limited to spells following a period of 12 or more months of non-use, among cancer-free people continuously enrolled for the 12 months prior to the spell starting, and for the three months after the spell starts. We report dangerous use indicators conditional on opioid use. 
to taking one 5-mg hydrocodone pill every four days over the initial spell. There are few signs of dangerous use among new users, at least in their first three months of opioid use and relative to the Medicare opioid users studied by Buchmueller and Carey (2018). For example, about 0.1 percent of new users have a very high daily MED, and about 3 percent have an overlapping claim. The corresponding numbers among all Medicare opioid users are 1.7 and 9 percent (Buchmueller and Carey, 2018).

The summary statistics suggest that initial prescriptions are fairly short, meaning limits on initial prescriptions may not bind often. We show this more clearly in Figure 2. which plots the distribution of days supply in states and months that do not have initial prescription limits (in unshaded bars) and in states-months with limits of 7 days or fewer (in shaded bars). The figure shows that even in states and months without any limits, most initial prescriptions are short. Indeed, 80 percent are for 7 days or fewer, 91 percent for 14 days or fewer, and 95 percent for 20 days or fewer. 9 Thus on their face it is unlikely initial prescription limits will have an effect for most new users, at least unless the limits are fairly tight. In Figure 3, we show further that initial prescriptions do not always conform to the statutory limits on days supply. The figure plots, for each state with an initial prescription limit, the share of initial prescriptions exceeding the limit (in months when the limits are in effect, and separately in months when the limits are not in effect). Prescriptions are more likely to be conforming when limits are in effect. However, for states with low limits, as many as half of initial prescriptions exceed the limits; for states with 7 days supply, 10-20 percent of prescriptions exceed the limit. These exceptions may well be legitimate (as the laws often allow for exceptions for those with non-acute pain such as cancer), but they provide further evidence that the laws often have limited bite.

9This figure pools surgical and non-surgical prescriptions. Even among prescriptions written by surgeons, long prescriptions are rare: 79 percent are for 7 days or fewer, and 95 percent for 14 days or fewer. 
Figure 2: Distribution of days supply in initial prescription

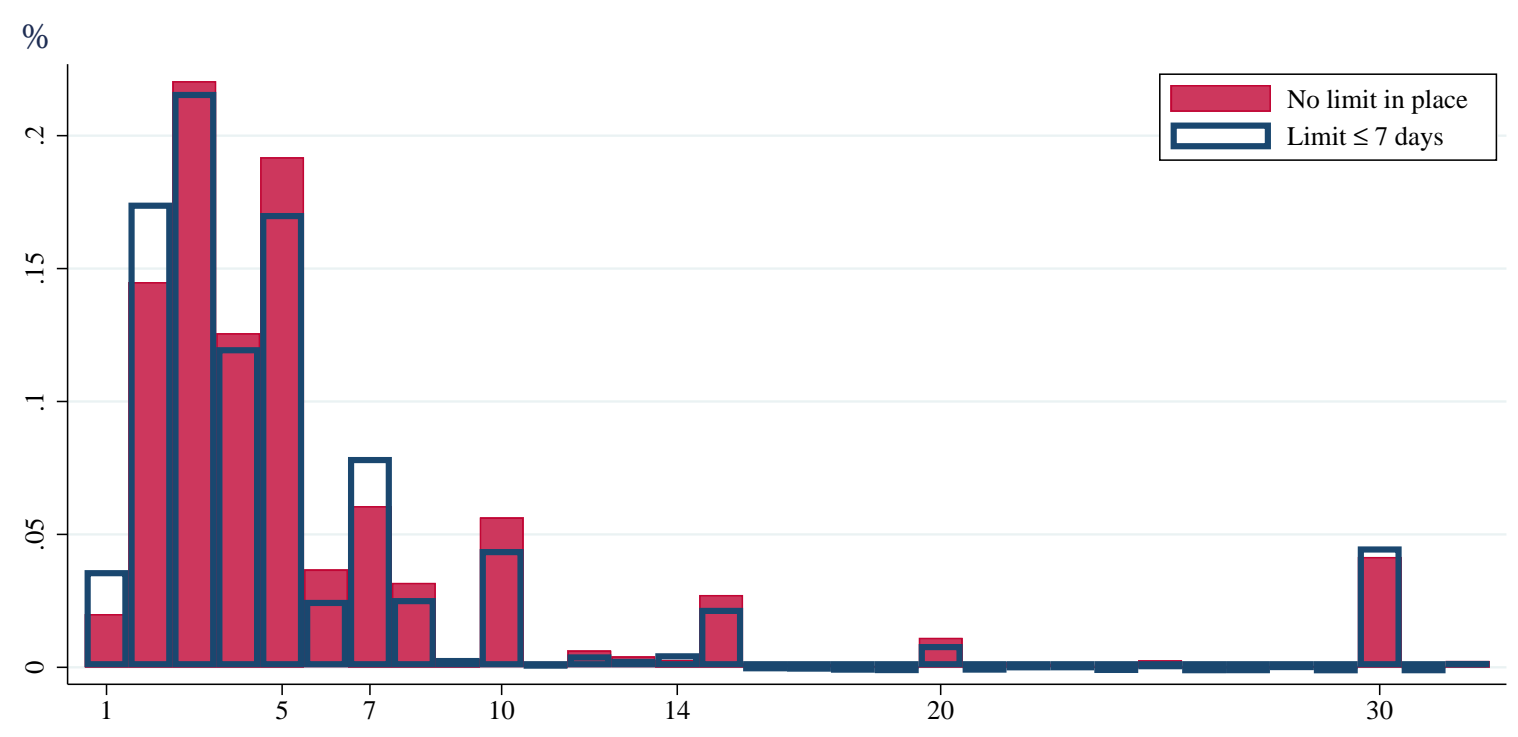

Notes: Figure shows the proportion of initial prescriptions with the indicated number of days supply, for states which never or have not yet implemented limits on days supply (hollow bars) and for states which have implemented limits of 7 days supply or fewer (solid bars).

Figure 3: Share of initial prescriptions above days supply limit, by state

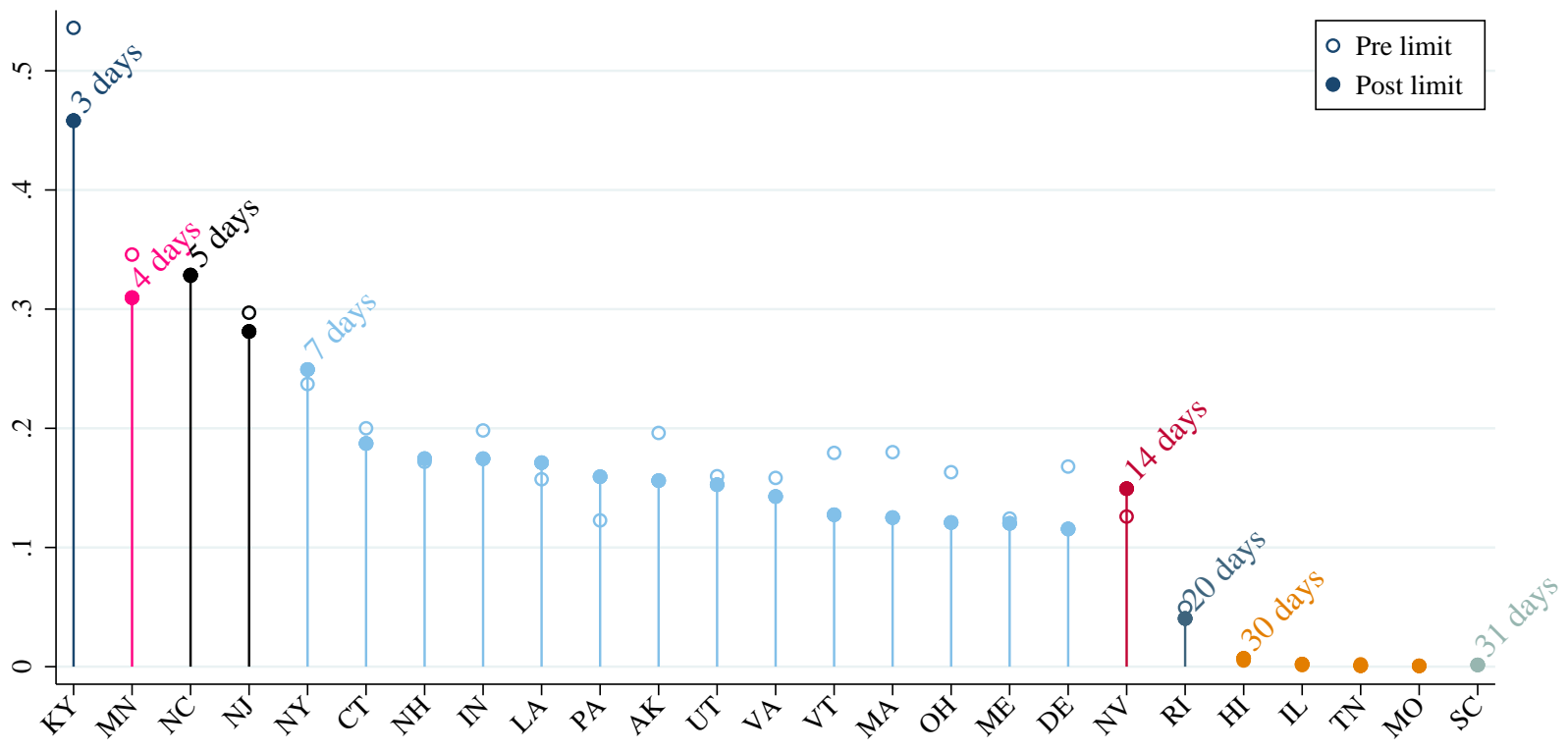

Notes: For each state with a limit on days supply in effect, we calculate the fraction of initial prescriptions above the statutory limit, using the sample described in the data section. 


\subsection{Empirical strategy}

Estimating equation Our goal is to estimate the effect of limits on initial prescriptions and MA-PDMPs on opioid utilization among new users. We therefore estimate regressions of the following form:

$$
y_{s t}=\alpha \text { Limit }_{s t}+\beta M A-P D M P_{s t}+\theta_{s}+\gamma_{t}+\varepsilon_{s t} .
$$

The specification controls for state and time (month-by-year) fixed effects. Our interest is in $\alpha$ and $\beta$, which give the differential change in $y_{s t}$ among states implementing limits on initial prescriptions or MA-PDMPs, relative to the change for control states.

Limit $_{s t}$ indicates if a state limits prescriptions for new opioid users to 14 days supply or fewer. This definition excludes 7 states with a limit on the initial prescription longer than 14 days. ${ }^{10}$ We chose this cutoff because the longer limits appear to rarely bind. (See』 Figure 2.) In principle we could analyze each limit separately, but power concerns motivated us to pool all limits 14 days and shorter. We consider robustness to narrower and wider definitions of Limit.

We define $M A-P D M P_{s t}$ as an indicator for states requiring at least some providers to check a PDMP in at least some circumstances, consistent with Buchmueller and Carey (2018). However some states require checking only in limited (such as only pain clinics) or discretionary (such as with a suspicion of abuse) circumstances. In robustness checks, we omit states with limited or discretionary access requirements.

The key coefficients, $\alpha$ and $\beta$, have a causal interpretation if changes in MA-PDMPs and limits on initial prescriptions are uncorrelated with other state-level changes in opioid use. Our time and state fixed effects control for many potential confounds. The time fixed effects, for example, control for national policies and guidelines like Oxycontin's reformulation and the CDC's prescribing guidelines. The state fixed effects control for permanent differences across states in propensity to prescribe opioids.

Threats to identification We remain particularly concerned with two broad threats

10 The states are Rhode Island (20 days); Hawaii, Illinois, Rhode Island, and Tennessee (all 30 days); South Carolina (31 days); and Maryland (strength is limited to the lowest effective dose, no limit on days supply). 
to our identifying assumptions. First, some states implemented packages of reforms, so there many other law changes at the same time that PDMPs become must-access or limits on initial prescriptions are introduced. Second, states hist hardest by the opioid epidemic may have been most likely to implement these reforms. While our state fixed effects control for time-invariant cross-state heterogeneity, we remain concerned about differential trends. Specifically, we are worried that high-use states have experienced particularly large declines in opioid use since the middle of our sample period. This is because policy makers and physicians have become aware of the dangers of opioid prescribing, prescribing has fallen, and it has had the most room to fall in high use states.

We address these concerns in turn. To address the first concern, we control for MAPDMPs; other policies are not robustly associated with declines in opioid use (Meara et al., 2016; Buchmueller and Carey, 2018). We also note that we end up finding positive effects of initial prescription limits. The concern that limits are implemented along with other legal changes would imply a downward bias in our estimate, and so, if anything, would suggest that we have underestimated the positive effects of initial prescription limits on opioid prescribing.

We address the second concern in two ways. First, we estimate event study models which allow us to explore if there are differential trends in the pre-period. We do not find evidence for such pre-trends. This is reassuring because it suggests that slow-moving trends in opioid use or prescribing do not drive our estimates. Nonetheless it is possible that these tests are underpowered to detect fast-moving trend shifts that could drive both opioid prescribing and state lawmaking. Our second test for such concerns is to examine policy impacts on a placebo outcome, benzodiazepine prescribing. This is a valid placebo in the sense that it is not directly affected by must-access provisions or initial prescription limits. It is, however, arguably a proxy for opioid demand, as benzodiazepines are often taken with opioids, benzodiazepine misuse has been growing at a similar rate as opioid misuse, and benzodiazepine misuse is associated with similar factors (Bachhuber et al., 2016; Lembke et al., 2018; Votaw et al., 2019). To the extent that state legal changes coincide with changes in the demand for prescription drugs, we would expect benzodiazepine prescribing to respond as well. 
Table 2: Extensive margin effects

\begin{tabular}{lcc}
\hline & Any initial prescription (x100) & $\begin{array}{c}\text { Days MED in initial prescription } \\
(1)\end{array}$ \\
\hline Limits & 0.048 & 0.037 \\
& $(0.023)$ & $(0.019)$ \\
PDMP & -0.029 & -0.026 \\
& $(0.013)$ & $(0.028)$ \\
& & \\
$\alpha=\beta$ & 0.005 & 0.161 \\
Mean DV & 1.145 & 0.571 \\
\hline
\end{tabular}

Notes: Table reports estimates of the coefficients on indicators for "initial prescription limits" and "must access PDMPs", obtained from estimating OLS regressions of the indicated variables against policy indicators, state fixed effects, and month-year fixed effects. MED is morphine equivalent days. The row labelled $\alpha=\beta$ reports p-values of the hypothesis that the coefficients on MAPDMPandLimitareequal.Robuststandarderrors, clusteredonstate, inparentheses.

\section{Results}

We begin by showing that initial prescription limits increase use on the "extensive margin," raising the probability of receiving an initial opioid prescription among the opioid naive and the total amount dispensed to opioid-naive enrollees. MA-PDMPs reduce use on this margin. We turn to the intensive margin to show that neither policy affects the amount received conditional on receiving an initial prescription. Next, we show that neither policy has an effect on extreme or dangerous use in the short run among new users. Finally, we present a variety of evidence establishing the validity and robustness of our our findings.

\subsection{Extensive margin}

Table 2 reports our extensive margin estimates. The first column shows the effect on the hazard of new use. Whereas we might have expected that initial prescription limits simply reduce the length of written prescriptions, with no extensive margin effect, we find that these limits are associated with a 4 percent increase in the hazard of new fills. MAPDMPs are associated a decrease in this outcome that is slightly smaller in magnitude, 
Figure 4: Effect distribution of days supply

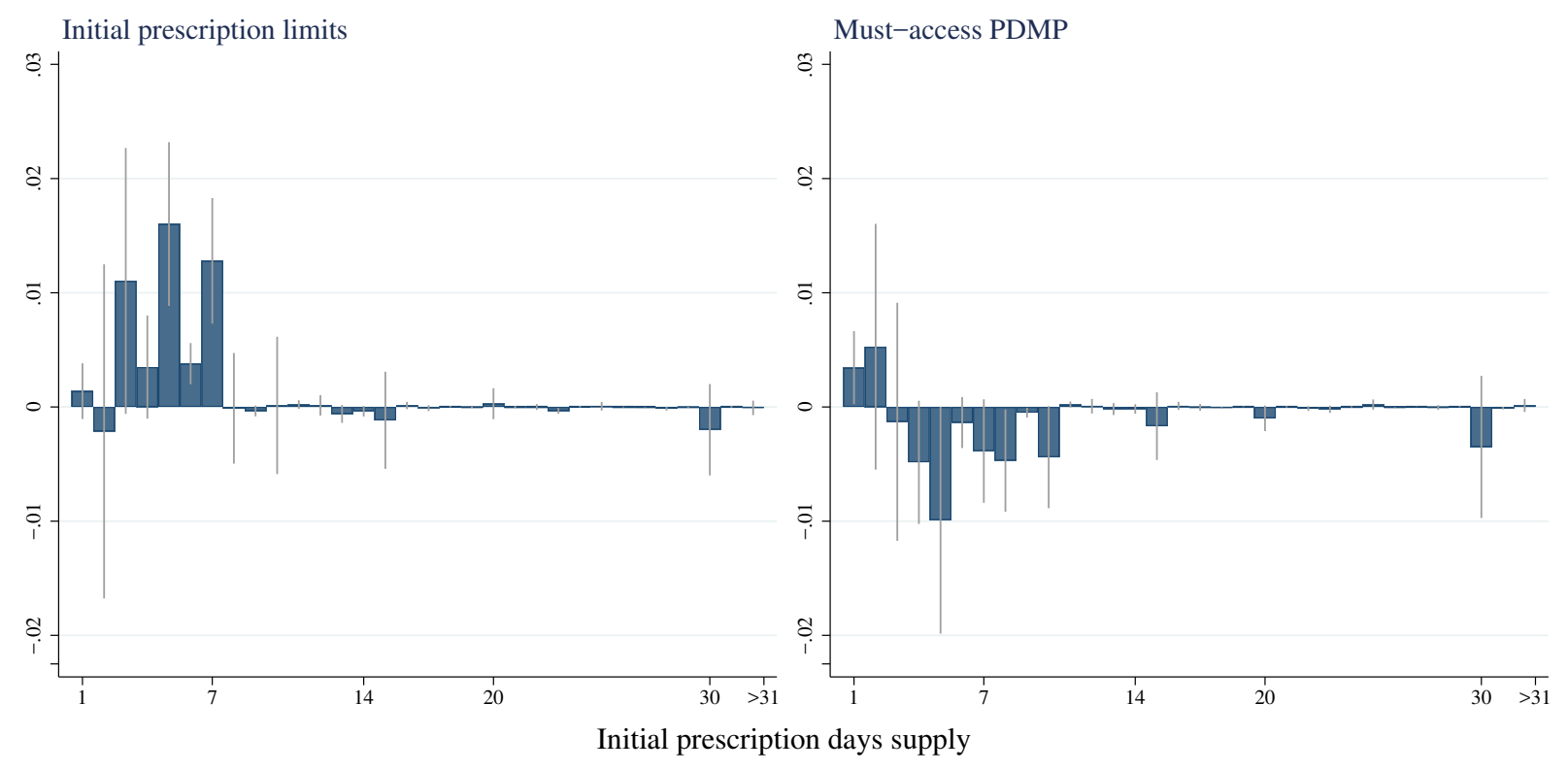

Notes: Figure shows the estimated coefficient on initial prescription limits (right panel) and MA-PDMP (left panel), obtained from Equation 1 with indicators for "initial prescription is for d days supply" as the dependent variable. Each point in each panel is from a separate regression.

about 2.5 percent. Both estimates are statistically significantly different from zero and from each other.

Although initial prescription limits therefore increase the number of new prescriptions, they could reduce the total amount of opioids dispensed to new patients if they result in substantially shorter prescriptions. In Column (2) we show that that morphineequivalent days dispensed to new patients actually increases following the enactment of initial prescription limits. The coefficient, which is marginally significant $(p=0.06)$, implies a 6 percent increase in the quantity of opioids dispensed.

We further investigate the surprising increase in prescribing in Figure 4. To construct the figure, we estimate Equation 1 with "filled an initial prescription for $\mathrm{d}$ days supply" as the dependent variable, and plot the estimated coefficients on Limits and MustAccessPDMP. The figure shows large clear increases in the hazard of having a short initial prescription induced by initial limit policies, with increases at each days supply up to seven. There are small decreases in the hazard of having a long prescription, 
Table 3: Extensive margin effects by provider type

\begin{tabular}{lcccccc}
\hline & \multicolumn{6}{c}{ Filled a prescription written by a... (x100) } \\
\cline { 2 - 7 } & $\begin{array}{c}\text { Physician } \\
(1)\end{array}$ & $\begin{array}{c}\text { PCP } \\
(2)\end{array}$ & $\begin{array}{c}\text { Surgeon } \\
(3)\end{array}$ & $\begin{array}{c}\text { Pain MD } \\
(4)\end{array}$ & $\begin{array}{c}\text { Dentist } \\
(5)\end{array}$ & $\begin{array}{c}\text { NP or PA } \\
(6)\end{array}$ \\
\hline Limits & 0.073 & 0.042 & 0.006 & -0.000 & 0.001 & 0.000 \\
& $(0.028)$ & $(0.012)$ & $(0.007)$ & $(0.000)$ & $(0.008)$ & $(0.008)$ \\
PDMP & -0.023 & -0.015 & 0.003 & -0.000 & -0.001 & 0.008 \\
& $(0.018)$ & $(0.009)$ & $(0.004)$ & $(0.000)$ & $(0.006)$ & $(0.006)$ \\
$\alpha=\beta$ & & & & & & \\
Mean DV & 0.000 & 0.000 & 0.649 & 0.637 & 0.715 & 0.378 \\
\hline
\end{tabular}

Notes: PCP is primary care provider, NP nurse practitioner, PA physician's assistant. Table reports estimates of the coefficients on indicators for "initial prescription limits" and "must access PDMPs", obtained from estimating OLS regressions of the indicated variables against policy indicators, state fixed effects, and month-year fixed effects. MED is morphine equivalent days. The row labelled $\alpha=\beta$ reports $p$-values of the hypothesis that the coefficients on MustAccessPDMP and Limits are equal. Robust standard errors, clustered on state, in parentheses.

but these decreases are small enough that they do not nearly offset the increase in short prescriptions. Initial prescription limits therefore increase opioids dispensed to new patients by increasing short prescriptions, without sufficiently reducing long prescriptions. MA-PDMPs, by contrast, reduce initial prescriptions written throughout the days supply distribution.

Who drives this extra prescribing? In Table 3, we look at the hazard of filling a new opioid prescription from specific types of providers. We find that physicians explain all the response, as initial prescription limits induce a 0.073 percent increase in the hazard of new physician prescribing-greater than the overall increase. Among physicians, primary care providers are especially responsive, as they account for seven-eighths of the overall response $(0.042 / 0.048)$ but a fifth of opioid prescribing. Physicians and, in particular, primary care providers also appear especially responsive to MA PDMPs. Other provider types are all relatively unresponsive to the initial prescription limits. 
Table 4: Intensive margin effects

\begin{tabular}{|c|c|c|c|c|c|c|}
\hline & \multicolumn{3}{|c|}{ Initial Prescription } & \multicolumn{3}{|c|}{ Initial Spell } \\
\hline & $\begin{array}{l}>7 \text { Days } \\
\text { supply } \\
(1)\end{array}$ & $\begin{array}{l}\text { Days } \\
\text { supply } \\
(2)\end{array}$ & $\begin{array}{l}\text { Days MED } \\
\text { (3) }\end{array}$ & $\begin{array}{l}\text { \# Fills } \\
\text { (4) }\end{array}$ & $\begin{array}{l}\text { Days } \\
\text { supply } \\
(5)\end{array}$ & $\begin{array}{l}\text { Days MED } \\
(6)\end{array}$ \\
\hline Limits & $\begin{array}{l}-0.040 \\
(0.007)\end{array}$ & $\begin{array}{c}-0.453 \\
(0.135)\end{array}$ & $\begin{array}{c}0.606 \\
(1.570)\end{array}$ & $\begin{array}{c}0.012 \\
(0.015)\end{array}$ & $\begin{array}{c}-0.611 \\
(0.313)\end{array}$ & $\begin{array}{c}1.163 \\
(4.491)\end{array}$ \\
\hline PDMP & $\begin{array}{c}-0.012 \\
(0.007)\end{array}$ & $\begin{array}{c}-0.194 \\
(0.129)\end{array}$ & $\begin{array}{c}-0.671 \\
(1.720)\end{array}$ & $\begin{array}{c}0.005 \\
(0.009)\end{array}$ & $\begin{array}{c}-0.233 \\
(0.269)\end{array}$ & $\begin{array}{c}-0.595 \\
(6.289)\end{array}$ \\
\hline$\alpha=\beta$ & 0.002 & 0.100 & 0.630 & 0.650 & 0.278 & 0.860 \\
\hline Mean DV & 0.199 & 6.376 & 49.829 & 1.473 & 10.899 & 114.506 \\
\hline
\end{tabular}

Notes: "DS" stands for days supply, and "MED" is morphine equivalent doses. Table reports estimates of the coefficients on indicators for "initial prescription limits" and "must access PDMPs", obtained from estimating OLS regressions of the indicated variables against policy indicators, state fixed effects, and monthyear fixed effects. The sample is limited to initial prescriptions, the unit of observation is a state-month, and all estimates are weighted by the number of initial prescriptions. The row labelled $\alpha=\beta$ reports $p$-values of the hypothesis that the coefficients on MustAccessPDMP and Limits are equal. Robust standard errors, clustered on state, in parentheses.

\subsection{Intensive margin}

We now turn to examine outcomes for patients who receive an initial prescription for an opioid. In Table 4, we present estimates of our main equation, looking at characteristics of the initial prescription (in Columns 1-3) and the initial spell (in Columns 4-6), conditional on filling an initial opioid prescription.

The results in Columns (1) and (2) show that both initial prescription limits and MAPDMPs reduce the length of the initial prescription, conditional on getting an initial prescription. Initial prescription limits reduce the length of the initial prescription received by about 7 percent, and reduce the probability that the initial prescription exceeds 7 days supply by 20 percent. On their own, these estimates might suggest that initial prescription limits succeed in their goal of shortening initial prescriptions. Combined with the extensive margin results, however, they indicate only that the limits increased the number of short prescriptions.

We might have feared that prescribers or patients responded to initial prescription 
limits with stronger or more frequent prescriptions. We do not see much evidence of such offsetting behavior. Column (3) shows that conditional on getting an initial prescription, limits do not significantly affect the days MED (a measure of opioid quantity). Columns (4)-(6) show that patients also do not fill more prescriptions, obtain substantially greater overall days supply, or greater days MED over the course of their initial spell. Thus conditional on getting an initial prescription, initial prescription limits appear to have minimal effects for the average patient-their main effect is simply increasing the frequency of short prescriptions.

Of course, the small average effects reported in Table 4 may mask meaningful responses in the tails of the opioid use distribution. We investigate tail behavior in Table 5. We consider five measures of extreme use (and all measures condition on receiving an initial prescription). In Columns (1) and (2), we look at high levels of use: filling prescriptions for more than 90 days supply total, or averaging more than 120 daily morphine-equivalent doses. In Columns (3) and (4), we look at two measures of drugseeking behavior: obtaining opioids from at least 3 prescribers, or filling overlapping opioid prescriptions. In Column (5) we look at an alternative measure of dangerous behavior: concurrent days supply of opioids and benzodiazepines. Across all outcomes we generally find no evidence that either initial prescription limits or MA-PDMPs reduce dangerous use or drug seeking behavior. While some of the coefficients appear individually significant, joint significance tests show that the MA-PDMP effects are not jointly significant, and neither are the initial prescription limit effects. 
Table 5: Effects on indicators of dangerous use during the initial spell

\begin{tabular}{lccccc}
\hline $\begin{array}{c}\text { Outcome } \\
\text { x100 }\end{array}$ & $\begin{array}{c}\geq 90 \\
\text { Days supply } \\
(1)\end{array}$ & $\begin{array}{c}\geq 120 \\
\text { Daily MED } \\
(2)\end{array}$ & $\begin{array}{c}\text { At least } 3 \\
\text { Prescribers } \\
(3)\end{array}$ & $\begin{array}{c}\text { Opioid } \\
\text { Overlap } \\
(4)\end{array}$ & $\begin{array}{c}\text { Concurrent } \\
\text { Benzodiazepine } \\
(5)\end{array}$ \\
\hline Limits & -0.059 & 0.001 & 0.152 & -0.271 & 0.028 \\
& $(0.113)$ & $(0.010)$ & $(0.178)$ & $(0.134)$ & $(0.242)$ \\
PDMP & -0.014 & -0.004 & 0.109 & -0.107 & -0.404 \\
& $(0.085)$ & $(0.013)$ & $(0.090)$ & $(0.148)$ & $(0.217)$ \\
& & & & & \\
$\alpha=\beta$ & 0.750 & 0.802 & 0.745 & 0.363 & 0.152 \\
Mean DV & 1.368 & 0.100 & 2.745 & 3.272 & 7.072 \\
\hline
\end{tabular}

Notes: "MED" is morphine equivalent doses. All outcomes are multiplied by 100 . Table reports estimates of the coefficients on indicators for "initial prescription limits" and "must access PDMPs", obtained from estimating OLS regressions of the indicated variables against policy indicators, state fixed effects, and monthyear fixed effects. The sample is limited to people with an initial prescription and all estimates are at the state-month level, weighted by the number of initial prescriptions. The row labelled $\alpha=\beta$ reports p-values of the hypothesis that the coefficients on $M A-P D M P$ and Limits are equal. Robust standard errors, clustered on state, in parentheses. 


\subsection{Validity tests}

We investigate the validity of our estimates in three sets of exercises. First, we show that trends appear roughly parallel in the pre-period. Next, we conduct a falsification exercise, showing that these laws have no impact on benzodiazepine prescribing (for the entire population of enrollees). Finally, we show that our results are robust to alternative ways of coding the key policies.

Parallel trends We test for parallel trends—our key identifying assumption—by estimating event-study type models. Although we have a relatively long pre-period for most states and both policies, we have a relatively short post-period, often just a few months for initial prescription limits, and not much longer for many states for MA-PDMPs. To show the pre-trends along with the overall effects that underlie our difference-in-difference models, we estimate the following event study models:

$$
\begin{aligned}
y_{s t}= & \sum_{-5 \leq h \leq 1, h \neq 0} \gamma_{h} 1\left\{\text { HalvesSinceLimit }_{s t}=h\right\} \\
& \left.+\gamma_{-6} 1\left\{\text { HalvesSinceLimit }_{s t} \leq-6 h\right\}+\gamma_{2} 1\left\{\text { HalvesSinceLimit }_{s t} \geq 2 h\right\}\right] \\
+ & {\left[\sum_{-5 \leq h \leq 2, h \neq 0} \theta_{h} 1\left\{\text { HalvesSinceMAPDMP } P_{s t}=h\right\}\right.} \\
& \left.+\theta_{-6} 1\left\{\text { HalvesSinceMAPDMP } P_{s t} \leq-6 h\right\}+\theta_{3} 1\left\{\text { HalvesSinceMAPDMP } P_{s t} \geq 3 h\right\}\right] \\
& +\alpha_{s}+\beta_{t}+\varepsilon_{s t},
\end{aligned}
$$

where $1\{$ HalvesSinceLimit st $=h\}$ is an indicator for $t$ is $h$ halves since the enactment of initial prescription limits in $s$, and $1\left\{\right.$ HalvesSince $\left.M A-P D M P_{s t}=h\right\}$ is defined analogously for MA-PDMPs. We estimate separate coefficients for each of the five halves prior to passage of each law. We estimate the effect of initial prescription limits in the first half after passage, and then we pool all subsequent periods, to show the longer run effect. As we have a longer post-period for many MA-PDMP states, we estimate separate effects in 
Figure 5: Event study results, key outcomes
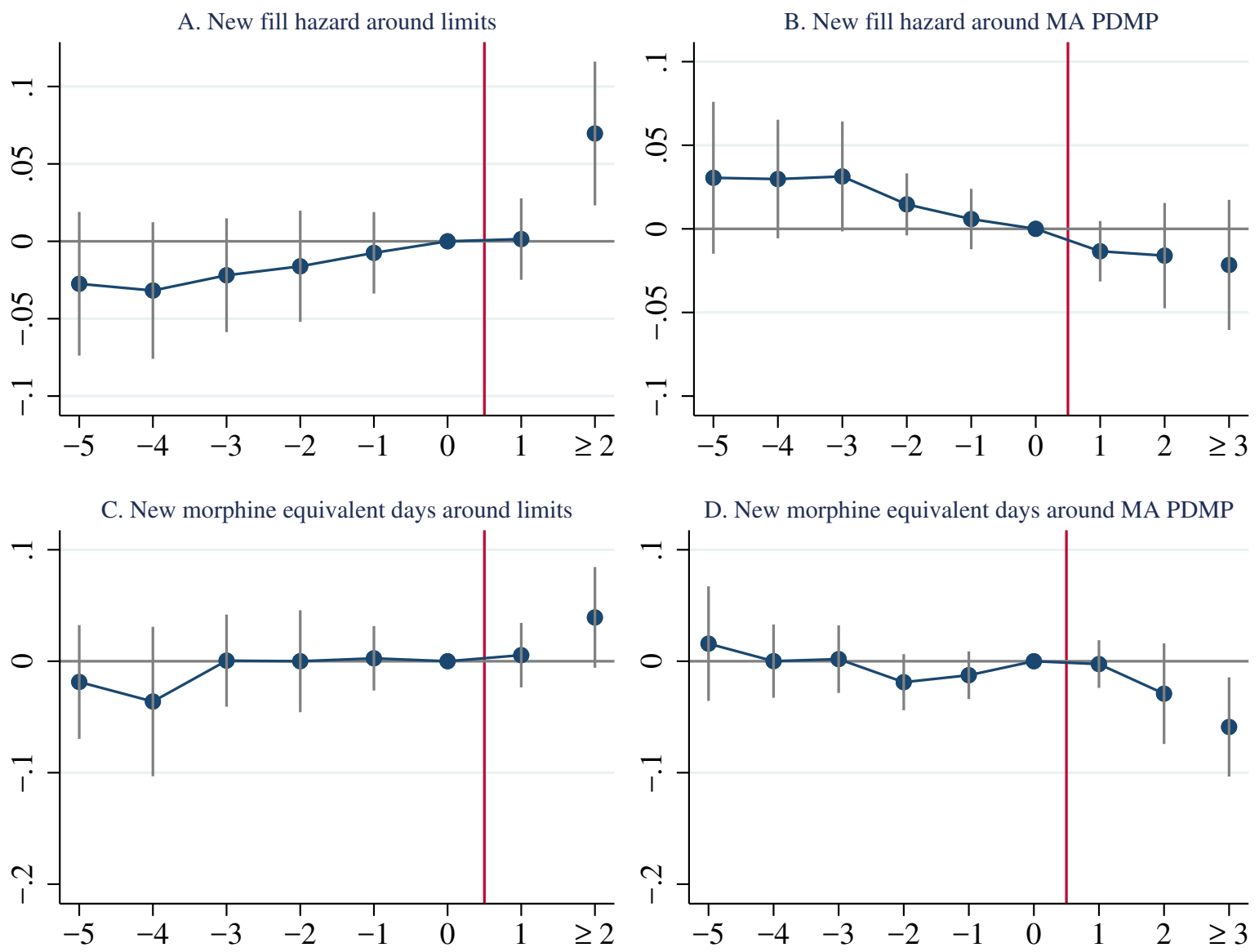

D. New morphine equivalent days around MA PDMP

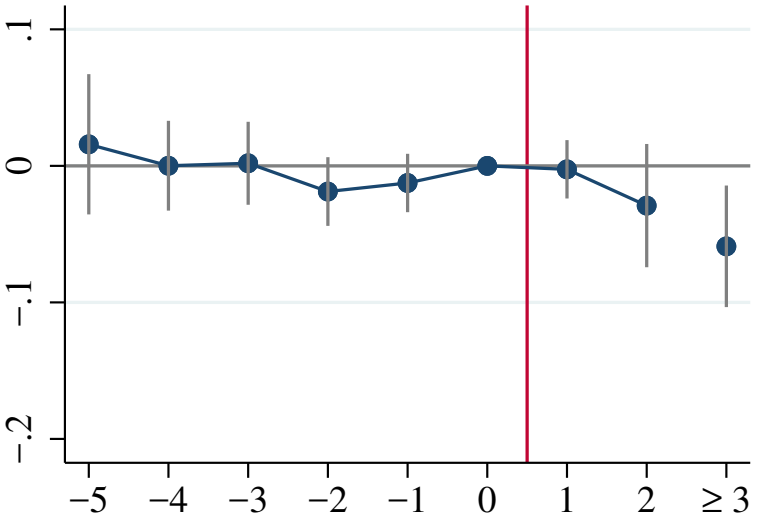

E. First fill days supply around limits

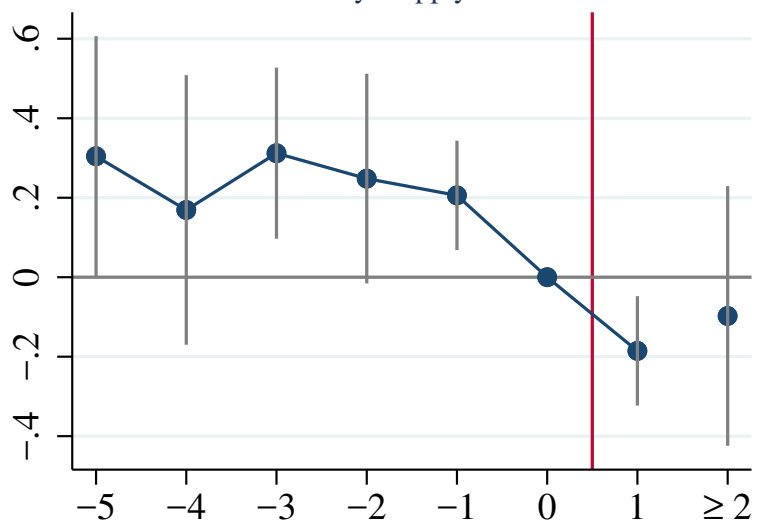

F. First fill days supply around MA PDMP

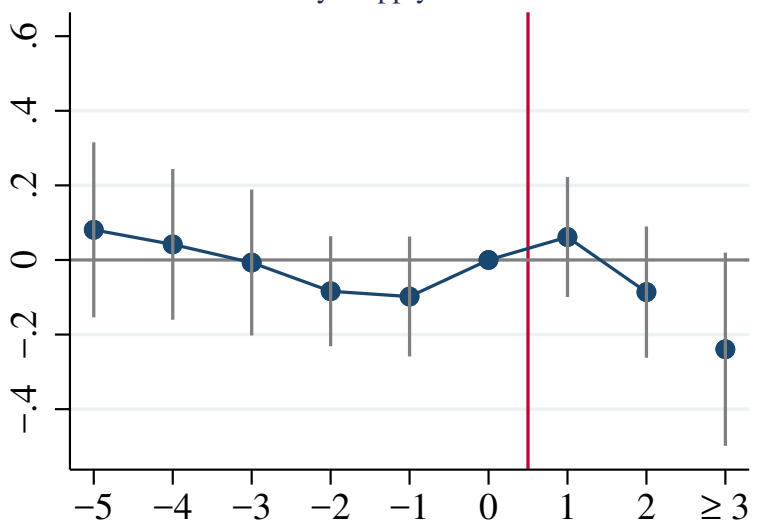

Half-years since policy change

Notes: Figure shows the estimated coefficients on half-years since MA-PDMP enactment (in the left panels) and half-years since initial prescription limits enactment (in the right panels), obtained from estimating Equation 2 for the indicated outcomes. 
the first and second half-years after enactment, before pooling all subsequent half-years. If the parallel trends assumption holds, we expect $\gamma_{m}=0$ for $m<0$.

We plot the event study coefficients in Figure 5, for three key outcomes: new fill hazard, morphine equivalent days dispensed to new users, and first fill days supply (i.e. the length of the initial prescription). We show the event study plots for the other intensive margin outcomes in Appendix Figure A.1. for the extreme outcomes in Appendix Figure A.2. Generally the pre-trends are insignificant, and we see little evidence of differential trends prior to policy enactment. However, one exception is that the initial prescription length falls in the first half prior to policy enactment, as shown in Panel E. This likely reflects some imprecision in the exact dating of the policy, as well as possible anticipatory behavior.

Falsification exercise One concern with our results is that they could be driven by state-specific changes in attitudes towards prescribing potentially dangerous substances, or in the demand for such substances. Our parallel trends analysis suggests that such changes, if present, would have to occur sharply around the timing of enactment of the laws. To provide evidence against this hypothesis, we look at the impact of initial prescription limits and MA-PDMPs on benzodiazepine prescribing, in the entire sample of enrollees (rather than opioid-naive, cancer-free, and continuously enrolled). We look at benzodiazepine use because it is not directly affected by our laws but it is arguably a proxy for underlying opioid demand.

Table 6 shows the results of re-estimating our main difference-in-differences model but looking at two measures of benzodiazepine use as the outcome. Column (1) looks at days supply of benzodiazepines dispensed per enrollee-month, and Column (2) looks at the probability of filling any prescription for benzodiazepines in a given month. For both outcomes, the impact of initial prescription limits and MA-PDMPs are small and statistically insignificant.

Robustness We examined the robustness of our findings to alternative codings of initial prescription limits and MA-PDMPs. We show the results of these robustness tests in Appendix Table A.3. Panel A re-presents our main estimates and in Panel B we adopt a stricter coding of initial prescription limits, only counting limits of 7 days or fewer. The 
Table 6: Effects on a placebo outcome, benzodiazepine use

\begin{tabular}{lcc}
\hline Outcome & $\begin{array}{c}\text { Benzodiazepine days supply } \\
(1)\end{array}$ & $\begin{array}{c}\text { Has at least one benzodiazepine claim } \\
(2)\end{array}$ \\
\hline Limits & -0.06037 & -0.00090 \\
& $(0.10877)$ & $(0.00374)$ \\
PDMP & 0.01787 & 0.00176 \\
& $(0.09445)$ & $(0.00291)$ \\
& & \\
$\alpha=\beta$ & 0.523 & 0.510 \\
Mean DV & 1.38013 & 0.05017 \\
\hline
\end{tabular}

Notes: Table reports the coefficients on indicators for "initial prescription limits" and "must access PDMPs", obtained from estimating OLS regressions of the indicated variables against policy indicators, state fixed effects, and month-year fixed effects. The sample includes all enrollees. All estimates are at the state-month level, weighted by the number of initial prescriptions. The row labelled $\alpha=\beta$ reports $\mathrm{p}$-values of the hypothesis that the coefficients on $M A-P D M P$ and Limits are equal. Robust standard errors, clustered on state, in parentheses.

resulting estimates for initial prescription limits are generally somewhat larger in magnitude, although never substantially so. In Panel C, we report the results of using a looser coding, treating all laws reported in Davis et al. (2019) as limits on initial prescriptions. This adds another 7 states to those with limits: six which limit days supplied to between 20 and 31, and one which does not limit days supply but does limit the initial prescription to the weakest effective does. Consistent with our expectation that looser limits are less likely to bind, we find that under this alternative coding, limits on initial prescriptions have an even smaller impact on days supply, and we continue to find slight offsetting effects later in the initial spell, resulting in higher daily MED.

We also considered an alternative coding of MA-PDMPs. Our baseline defines MAPDMPs as those which require at least some providers to access the PDMP in at least some circumstance. As Buchmueller and Carey (2018) note, the weakest such PDMPs require providers to access only in limited (e.g.for Methadone prescriptions) or discretionary (e.g. only when the provider suspects abuse) circumstances. We therefore reestimated our models assuming a stricter definition of must-access which treats such limited or discretionary requirements as non-must-access. The alternative coding and dating 
of MA-PDMPs may be seen in Appendix Table A.1.

The new difference-in-difference estimates are in Panel D of Appendix Table A.3. This alternative coding of MA-PDMPs produces very similar estimates, in part because many of the states with limited or discretionary access requirements subsequently passed stricter must-access requirements, making the laws highly correlated.

\section{Mechanisms}

It is perhaps surprising that initial prescription limits increase the hazard of initial opioid use, and that MA-PDMPs reduce it ${ }^{11}$ In this section, we discuss the possible mechanisms generating this result. We caution that this discussion is speculative as we are ex post rationalizing a surprising result.

\subsection{Explaining the initial prescription limits results}

We consider three possible mechanisms for the finding that initial prescription limits increase the hazard of initial prescriptions. Our leading explanation is that the limit acts as a reference point for prescribers, signalling a safe or acceptable level, and therefore increasing prescribing below that level. We rule out two alternative explanations: that compensatory behavior such as more refills by patients or providers ends up undermining initial prescription limits, and that low out-of-pocket prices for shorter prescriptions explains the higher rate of observed fills in the claims data.

The most likely mechanism that we believe explains these results is that initial prescription limits act as reference points. The hypothesis here is that physicians, who have recently been exposed to many warnings urging caution in opioid prescribing, see a law with a limit of 7 days supply and come to think that 7 days is relatively safe or socially acceptable. Thus they end up writing a 7 day supply for a patient on the margin of receiving a prescription, who would otherwise receive no opioid. This reference point hypothesis does not necessarily imply that some physicians increased their prescribing immediately

111 It was surprising to us; we initially hypothesized initial limit policies would reduce the length but not frequency of new opioid use. 
when states passed these laws. Rather, these laws were passed in a context of falling opioid prescribing and rising skepticism about opioids. This hypothesis implies only that initial prescription limits could reduce the decline in prescribing.

The reference point hypothesis is consistent with several features of the data. First, it implies that initial prescription limits increase only prescriptions perceived as safe, i.e. short prescriptions, which is what we see in the data. It is also arguably consistent with the effect being concentrated among primary care providers, who may need to keep track of many different prescribing guidelines, and may therefore especially rely on heuristics. Third, it is consistent with the non-immediate extensive margin response to the limits evident in Figure 5, the event study figure, as a reference point would likely take time to develop.

Other plausible mechanisms do not fit the data as well. One possible way for initial prescription limits to raise opioid dispensed to new users and in general is through compensatory behavior. For example, given a short initial prescription, patients might seek or physicians might write stronger prescriptions or more subsequent prescriptions. We find no evidence for that view, as the strength does not increase and neither does the number of prescriptions in the initial spell $[2$

Still another possibility is that initial prescription limits increase initial use by changing the number of filled prescriptions rather than the number of written prescriptions. To understand this hypothesis, note that we only observed filled prescriptions in our claims data, not unfilled prescriptions written by physicians. If initial prescription limits induce physicians to write shorter prescriptions that are cheaper for patients, then perhaps we observe more fills because there are fewer unfilled, expensive prescriptions.

Although at first this seems a potential explanation, we find this mechanism implausible because there are not substantial cost differences between short and long prescriptions. Appendix Figure A.3 shows that the copay per days supply of a given drug actually declines in prescription length, so longer prescriptions are cheaper on a per day basis $\mathrm{13}^{13}$

${ }_{12}^{12}$ We also looked at whether initial prescription limits increased the number of pills per prescription, to facilitate stretching the prescription out. Our (unreported) estimates indicate that they do not.

13 Every drug claim in our data records a copay, which we interpret as the total out-of-pocket cost to the patient of filling the prescription. 
The total copay (not per days supply) increases with days supply, from about $\$ 6$ for a 7 days supply to about $\$ 10$ for a 20 days supply. Extremely tight liquidity constraints might suffice to keep prevent some patients from filling a 20 days supply but not a 7 day supply. We think it unlikely that this extra $\$ 4$ would be decisive, however, because we are studying commercially insured patients who likely have some liquidity, and because we expect that patients seeking an opioid for acute pain are unlikely to be deterred by a few dollars.

\subsection{Explaining the MA-PDMP results}

We find that MA-PDMPs reduce prescribing to new patients. We hypothesize two possible mechanisms for this result. First, MA-PDMPs create several fixed costs of prescribing opioids even to new patients, because they require prescribers to register with the system and log each prescription, and generate a sense that the prescribers actions are being scrutinized. Second, MA-PDMPs inform physicians that opioids are more dangerous or more frequently abused than they had believed, by showing them the frequency with which patients engage in doctor shopping.

Although we cannot fully separate these mechanisms, we find the fixed cost of prescribing mechanism more plausible. This hypothesis is consistent with the evidence in Buchmueller et al. (2018), who find that when Kentucky introduced its MA-PDMP, opioid prescribing fell, and many low-volume prescribers stopped prescribing entirely, relative to a control group of Indiana prescribers. Buchmueller et al. indicate that a likely reason for this extensive margin response is that Kentucky's must-access provisions required prescribers to register with the database, creating a fixed cost of prescribing any opioid. On the other hand, we think it is unlikely that MA-PDMPs informed prescribers about the general dangers of opioid prescribing. Among new patients, our evidence suggests that opioid are rarely misused, at least in the short period we follow in this analysis. Prescribers would have had to have very low priors on the probability of misuse for this information to push them to prescribe less. 


\section{Discussion and conclusions}

In response to the opioid epidemic, many states have now passed laws limiting the length of initial opioid prescriptions written for patients with acute pain. Policy makers hope that these laws reduce the quantity of opioids dispensed to new users, to prevent unintentional addiction and cut down the stock of opioids available for diversion. We investigate the effects of these limits using difference-in-difference models and a sample of new opioid users derived from claims data of a large commercial health insurer. Our findings suggest that these laws have not achieved their goal. Although they are effective in the narrow sense that they reduce the length of the initial prescription, they are less effective in reducing overall opioid dispensing to new users. We find that initial limit policies induce a greater number of initial prescriptions, resulting in more opioids dispensed to new users. By contrast, MA-PDMPs are effective in reducing opioids dispensed to new users in terms of days supply (as well as reducing the extreme outcomes they were primarily intended to target): they reduce the hazard of initial prescription as well as the length of the initial prescription, as expected, and we do not observe an increase in the subsequent number of prescriptions.

Our results have implications for policy makers hoping to slow the rate of new opioid use. First, initial prescription laws may be too narrowly targeted, or allow too many exceptions to be effective. On most measures these laws do not appear to reduce use, and so it is unlikely that they are preventing development of addiction disorders or dependence. Second, MA-PDMPs may be a more effective tool even at reducing initial prescriptions. Thus it may be worthwhile for future research to examine implications of further modifications within MA-PDMPs, such as integration with electronic health records.

However, our results are subject to at least two limitations. First, our sample consists of commercially insured patients, thus we are not able to claim representativeness of results for the population as a whole. However, we believe our focus on commercially insured population is a valuable complement to the existing literature, especially because it encompasses more age groups affected by high opioid overdose mortality, relative to the more-often-studied Medicare population. Second, because we study laws which were en- 
acted only recently, we are unable to examine outcomes beyond about three months after the initial prescription. It may be that initial limit policies reduce adverse outcomes at a greater time horizon; the laws likely aim to reduce misuse at much greater time horizons.

Our results may have broader implications for substance use policy. We found that a policy that explicitly targeted new use was not effective and had negative unintended consequences, but a policy that raised the cost of prescribing has desirable effects beyond the intended ones. We speculate that, in general, limits on new use or overall use are unlikely to be an effective tool. Such limits are only appealing for substances whose harms and benefits are ambiguous. But it is in exactly that situation when a limit may signal a safe or acceptable level, generating unintentionally higher usage. Other policies such as explicit requirements for step therapy may be more effective, as may be policies that raise the cost of prescribing. 


\section{References}

Alpert, Abby, David Powell, and Rosalie Liccardo Pacula, "Supply-Side Drug Policy in the Presence of Substitutes: Evidence from the Introduction of Abuse-Deterrent Opioids," American Economic Journal: Economic Policy, 2018, 10.

Bachhuber, Marcus A., Sean Hennessy, Chinazo O. Cunningham, and Joanna L. Starrels, "Increasing Benzodiazepine Prescriptions and Overdose Mortality in the United States, 1996âĂŞ2013," American Journal of Public Health, 2016, 106 (4), 686-688. PMID: 26890165.

Barnett, Michael L., Andrew R. Olenski, and Anupam B Jena, “Opioid-Prescribing Patterns of Emergency Physicians and Risk of Long-Term Use," New England Journal of Medicine, feb 2017, 376 (7), 663-673.

Buchmueller, Thomas C. and Colleen Carey, "The effect of prescription drug monitoring programs on opioid utilization in Medicare," American Economic Journal: Economic Policy, 2018, 10, 77-112.

_, Colleen M. Carey, and Giacomo Meille, "How Well Do Doctors Know Their Patients? Evidence from a Mandatory Access Prescription Drug Monitoring Program," October 2018. Unpublished working paper.

Butler, Megan M, Rachel M Ancona, Gillian A Beauchamp, Cyrus K Yamin, Erin L Winstanley, Kimberly W Hart, Andrew H Ruffner, Shawn W. Ryan, Richard J Ryan, Christopher J Lindsell, and Michael S Lyons, "Emergency Department Prescription Opioids as an Initial Exposure Preceding Addiction," Annals of Emergency Medicine, aug 2016, 68 (2), 202-208.

Case, Anne and Angus Deaton, "Rising morbidity and mortality in midlife among white non-Hispanic Americans in the 21st century," Proceedings of the National Academy of Sciences, 2015, 112, 15078-15083.

Centers for Disease Control and Prevention, "2018 Annual Surveillance Report of Drug-Related Risks and Outcomes," Technical Report August 2018. Available at https://www.cdc.gov/drugoverdose/pdf/pubs/2018-cdc-drug-su rveillance-report.pdf

Chen, Li Hui, Molly Hedegaard, and Margaraet Warner, "Drug-poisoning deaths involving opioid analgesics: United States, 1999-2011," Technical Report September 2014. NCHS Data Brief. No. 166.

Cotti, Chad, Erik Nesson, and Nathan Tefft, "The Effects of Tobacco Control Policies on Taboacco Products, Tar, and Nicotine Purchases Among Adults: Evidence from Household Panel Data," American Economic Journal: Economic Policy, 2016, 8 (4), 103-123.

Dasgupta, N., M.J. Funk, S. Proescholdbell, A. Hirsch, K.M. Ribisl, and S. Marshall, “Cohort study of the impact of high-dose opioid analgesics on overdose mortality," Pain Medicine (United States), 2016, 17 (1), 85-98. 
Dave, Dhaval, Monica Deza, and Brady P. Horn, "Prescription Drug Monitoring Programs, Opioid Abuse, and Crime," August 2018. NBER Working Paper No. 24975.

Davis, Corey S., Amy Judd Liberman, Hector Herandez-Delgado, and Carli Suba, "Laws limiting the initial prescribing or dispensing of opioids for acute pain in the United States: A national systematic legal review," Drug and Alcohol Dependence, 2019, 194, 166-172.

Dillender, Marcus, "What happens when the insurer can say no? Assessing prior authorization as a tool to prevent high-risk prescriptions and to lowerÂăcosts," Journal of Public Economics, 2018, 165, 170 - 200.

Dowell, Deborah, Tamara M. Haegerich, and Roger Chou, "CDC Guideline for Prescribing Opioids for Chronic Pain âĂT United States, 2016," MMWR Recomm Rep, 2016, 65, 1-49. http://dx.doi.org/10.15585/mmwr.rr6501e1External.

Evans, William N. and Matthew C. Farrelly, "The compensating Behavior of Smokers: Taxes, Tar, and Nicotine," RAND Journal of Economics, 1998, 29 (3), 578-95.

_ , Ethan Lieber, and Patrick Power, "How the reformulation of Oxycontin ignited the heroin epidemic," Review of Economics and Statistics, 2019, 101.

Han, Beth, Wilson M. Compton, Carlos Blanco, Elizabeth Crane, Jinhee Lee, and Christopher M. Jones, "Prescription Opioid Use, Misuse, and Use Disorders in U.S. Adults: 2015 National Survey on Drug Use and HealthPrescription Opioid Use, Misuse, and Use Disorders in U.S. Adults," Annals of Internal Medicine, 09 2017, 167 (5), 293-301.

Hedegaard, Holly, Matgaret Warner, and Arialdi M. Mini no, "Drug overdose deaths in the United States, 1999-2016," Technical Report December 2017. NCHS Data Brief. No. 294.

International Narcotics Control Board, "Report of the International Narcotics Control Board on the availability of internaionally controlled drugs: Ensuring adequate access for medical and scientific purposes.," June 2010. Available at http://www.incb.org/documents/Publications/AnnualReports/AR20 10/Supplement-AR10_availability_English.pdf.

Jones, Jermaine D., Shanthi Mogali, and Sandra D. Comer, "Polydrug abuse: A review of opioid and benzodiazepine combination use," Drug and Alcohol Dependence, 2012, 125, 8-18.

Kasich, John., “(@JohnKasich),” Tweet, Apr 2017.

Kilby, Angela E., "Opioids for the masses: Welfare Tradeoffs in the Regulation of Narcotic Pain Medications," November 2015. Unpublished working paper.

Kochanek, Kenneth D., Elizabeth Arias, and Brigham Bastian, "The effect of changes in selected age-specific causes of death," Technical Report June 2016. NCHS Data Brief. No. 250. 
Lembke, Anna, Jennifer Papac, and Keith Humphreys, "Our Other Prescription Drug Problem," New England Journal of Medicine, 2018, 378, 693-695. 10.1056/NEJMp1715050.

Lipsari, Rachel N. and Arthur Hughes, "How people obtain the prescription pain relievers they misuse," January 2017. The CBHSQ Report: January 12, 2017. Center for Behavioral Health Statistics and Quality, Substance Abuse and Mental Health Services Administration, Rockville, MD.

Mallatt, Justine, "The Effect of Prescription Drug Monitoring Programs on Opioid Prescriptions and Heroin Crime Rates," October 2017. Unpublished working paper.

Meara, Ellen, Jill R. Horowitz, Wilson Powell, Lynn McClelland, Weiping Zhou, A. James O'Malley, and Nancy E. Morden, "State legal restrictions and precription opioid use among disabled adults," New England Journal of Medicine, 2016, 375, 44-53.

Merboth, M. K. and Susan Ann Barnason, "Managing Pain: The Fifth Vital Sign," The Nursing Clinics of North America, 2000, 35, 375-383.

Mularski, Richard A., Foy White-Chu, Devorah Overbay, Lois Miller, Steven M. Asch, and Linda Ganzini, "Measuing Pain as the 5th Vital Sign Does Not Improve Quality of Pain Management," Journal of General Internal Medicine, 2006, 21, 607-612.

Prescription Drug Monitoring Program Training and Technical Assistance, "Calculating daily morphine milligram equivalents," February 2013. Technical Assistance Guide No. 01-13.

Ruhm, Christopher J., "Corrected US opioid-involved drug poisoning deaths and mortality rates, 1999-2015," Addiction, 2018, 113.

Scholl, Laurence, Puja Seth, Mbabazi Kariisa, Nana Wilson, and Grant Baldwin, "Drug and Opioid-Involved Overdose Deaths: United States, 2013-2017," Morbidity and Mortality Weekly Report, 2019, 67, 1419-1427.

Shah, Anuj, Corey J. Hayes, and Braddley C. Martin, "Characteristics of initial prescription episodes and likelihood of long-term opioid use - United States, 206-2015," Morbidity and Mortality Weekly Report, 2017, 10, 265-269.

Surratt, Hilary L., Catherine O'Grady, Steven P. Kurtz, Yamilka Stivers, Theodore J. Cicer, Richard C. Dart, and Minxing Chen, "Reductions in prescription opioid diversion following recent legislative interventions in Florida," Phamacoepidemiology and Drug Safety, 2014, 23, 317-320.

Tompkins, D. Andrew, J. Greg Hobelmann, and Peggy Compton, "Providing chronic pain management in the "Fifth Vital Sign" Era: Historical and treatment perspectives on a modern-day medical dilemma," Drug and Alcohol Dependence, 2017, 173, S11-S21.

Van Zee, Art, "The promotion and marketing of oxycontin: Commercial triumph, public health tragedy.," American Journal of Public Health, 2009, 99, 221-227. 
Votaw, Victoria R., Rachel Geyer, Maya M.Rieselbach, and R. Kathryn McHugh, "The epidemiology of benzodiazepine misuse: A systematic review," Drug and Alcohol Dependence, 2019, 200, 95-114.

White, Jason M. and Rodney J. Irvine, "Mechanisms of fatal opioid overdose," Addiction, July 1999, 94, 961-972. 
Table A.1: Policy implementation dates and notes, by state

\begin{tabular}{|c|c|c|c|c|c|}
\hline \multirow[b]{2}{*}{ State } & \multicolumn{3}{|c|}{ Initial prescription limits } & \multicolumn{2}{|c|}{ Must access PDMP } \\
\hline & Effective date & Max days & Other limits & Effective date & Alternative date \\
\hline \multirow{2}{*}{\multicolumn{6}{|c|}{$\mathrm{AL}$}} \\
\hline & & & & & \\
\hline $\mathrm{AR}$ & & & & 2017m1 & \\
\hline $\mathrm{AZ}$ & & & & $2017 \mathrm{~m} 10$ & \\
\hline CA & & & & 2018m4 & \\
\hline \multicolumn{6}{|l|}{$\mathrm{CO}$} \\
\hline $\mathrm{CT}$ & $2016 \mathrm{~m} 7$ & 7 & None & $2015 \mathrm{~m} 10$ & \\
\hline \multicolumn{6}{|l|}{ DC } \\
\hline $\mathrm{DE}$ & $2017 \mathrm{~m} 4$ & 7 & None & $2012 \mathrm{~m} 3$ & No must access PDMPa \\
\hline \multicolumn{6}{|l|}{ FL } \\
\hline GA & & & & $2014 \mathrm{~m} 7$ & \\
\hline $\mathrm{HI}$ & $2016 \mathrm{~m} 7$ & 30 & None & & \\
\hline \multicolumn{6}{|l|}{ IA } \\
\hline \multicolumn{6}{|l|}{ ID } \\
\hline IL & $2012 \mathrm{~m} 1$ & 30 & None & $2018 \mathrm{~m} 1$ & \\
\hline IN & 2017m7 & 7 & None & $2014 \mathrm{~m} 7$ & \\
\hline \multicolumn{6}{|l|}{ KS } \\
\hline KY & $2017 \mathrm{~m} 6$ & 3 & None & $2012 \mathrm{~m} 7$ & \\
\hline LA & $2017 \mathrm{~m} 8$ & 7 & None & $2008 \mathrm{~m} 1$ & No must access PDMP \\
\hline MA & $2016 \mathrm{~m} 3$ & 7 & None & $2014 \mathrm{~m} 7$ & \\
\hline MD & $2017 \mathrm{~m} 5$ & & Lowest effective dose & $2018 \mathrm{~m} 7$ & \\
\hline ME & $2017 \mathrm{~m} 1$ & 7 & 100 MME per day & & \\
\hline \multicolumn{6}{|c|}{ 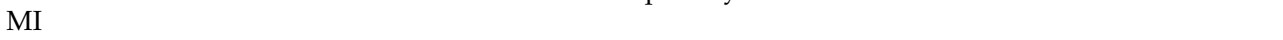 } \\
\hline $\mathrm{MN}$ & 2017m7 & 4 & None & 2017m1 & \\
\hline $\mathrm{MO}$ & $1988 \mathrm{~m} 12$ & 30 & None & & \\
\hline \multicolumn{6}{|l|}{ MS } \\
\hline \multicolumn{6}{|l|}{ MT } \\
\hline $\mathrm{NC}$ & $2018 \mathrm{~m} 1$ & 5 & None & & \\
\hline \multicolumn{6}{|l|}{ ND } \\
\hline \multicolumn{6}{|l|}{ NE } \\
\hline $\mathrm{NH}$ & 2017m1 & 7 & Lowest effective dose & 2016m1 & \\
\hline NJ & $2017 \mathrm{~m} 5$ & 5 & Lowest effective dose & $2015 \mathrm{~m} 11$ & \\
\hline NM & & & & $2012 \mathrm{~m} 9$ & \\
\hline NV & $2017 \mathrm{~m} 6$ & 14 & 90 MME per day & $2007 \mathrm{~m} 10$ & $2015 \mathrm{~m} 10^{c}$ \\
\hline NY & $2016 \mathrm{~m} 7$ & 7 & None & $2013 m 8$ & \\
\hline $\mathrm{OH}$ & $2017 \mathrm{~m} 8$ & 7 & 30 MME per day & $2012 \mathrm{~m} 3$ & $2015 \mathrm{~m} 12^{\mathrm{c}}$ \\
\hline OK & & & & $2011 \mathrm{~m} 3$ & $2015 \mathrm{~m} 11^{\mathrm{d}}$ \\
\hline \multicolumn{6}{|l|}{ OR } \\
\hline PA & $2017 \mathrm{~m} 1$ & 7 & None & 2017m1 & \\
\hline RI & $2017 \mathrm{~m} 3$ & 20 & 30 MME per day & $2016 \mathrm{~m} 6$ & \\
\hline SC & $2007 \mathrm{~m} 6$ & 31 & None & 2017m5 & \\
\hline \multicolumn{6}{|l|}{ SD } \\
\hline $\mathrm{TN}$ & $2013 \mathrm{~m} 10$ & 30 & None & $2013 \mathrm{~m} 7$ & \\
\hline TX & & & & $2019 \mathrm{~m} 9$ & \\
\hline UT & $2017 \mathrm{~m} 3$ & 7 & None & $2017 \mathrm{~m} 5$ & \\
\hline VA & $2017 \mathrm{~m} 3$ & 7 & None & $2015 \mathrm{~m} 7$ & \\
\hline VT & $2017 \mathrm{~m} 7$ & 7 & Varies by Pain Level & $2015 \mathrm{~m} 5$ & $2013 \mathrm{~m} 11^{\mathrm{e}}$ \\
\hline \multicolumn{6}{|c|}{ ק. } \\
\hline \multicolumn{6}{|l|}{ WI } \\
\hline WV & & & & $2012 \mathrm{~m} 6$ & \\
\hline WY & & & & & \\
\hline
\end{tabular}

Notes: Table reports the effective date of states' limits on initial prescriptions and of MA-PDMP laws. For states with limits, we report the maximum allowed days supply (if limited) and any other limits on the prescription (if any). We note ambiguities in the dating of MA-PDMPs and provide alternative dates where such ambiguity exists. ${ }^{a}$ PDMP requires access only if providers have a reasonable suspicion of abuse. ${ }^{b}$ Only pain clinics must access. ${ }^{\mathrm{c}}$ Initial PDMP required access only with a reasonable suspicion of abuse; access laws later strengthened. ${ }^{\mathrm{d}}$ Only methadone clinics must access (until 12/2015). ${ }^{e}$ Until 5/2015, access required only for patients reporting their prescription was lost or destroyed. 
Table A.2: Sample construction and sample size

\begin{tabular}{lrr}
\hline & Enrollees & Enrollee-Months \\
\hline & & \\
A. 20 percent sample of all enrollees & \\
\hline All & $11,916,182$ & $371,597,845$ \\
Enrolled $t-11$ to $t$ & $8,269,520$ & $245,493,810$ \\
Enrolled $t-11$ to $t+3$ & $7,144,063$ & $228,452,677$ \\
In 50 states + DC & $7,050,728$ & $225,762,240$ \\
No cancer & $6,949,041$ & $211,041,311$ \\
& \\
B. 100 percent sample of all controlled substance recipients \\
All & $22,264,546$ & $1,029,010,777$ \\
Enrolled $t-11$ to $t$ & $19,259,589$ & $753,973,937$ \\
Enrolled $t-11$ to $t+3$ & $17,695,352$ & $712,189,870$ \\
In 50 states + DC & $17,636,425$ & $707,568,491$ \\
No cancer & $17,343,695$ & $653,119,778$ \\
\hline
\end{tabular}

Notes: Table shows how our sample size changes as we impose our sample restrictions. The 20 percent sample is a random sample of all enrollees, and the 100 percent sample consists of all enrollees who filled a prescription for at least one controlled substance. 
Table A.3: Robustness of main difference-in-differences estimates

\begin{tabular}{|c|c|c|c|c|c|c|c|c|c|c|c|c|c|}
\hline & \multicolumn{2}{|c|}{ Extensive margin } & \multicolumn{3}{|c|}{ Initial prescription } & \multicolumn{3}{|c|}{ Initial spell } & \multicolumn{5}{|c|}{ Extreme outcomes } \\
\hline & $\begin{array}{c}\text { Hazard } \\
\text { (1) }\end{array}$ & $\begin{array}{c}\text { New Days } \\
\text { MED } \\
\text { (2) }\end{array}$ & $\begin{array}{c}>7 \text { DS } \\
(3)\end{array}$ & $\begin{array}{c}\text { Days } \\
\text { Supply } \\
(4)\end{array}$ & $\begin{array}{l}\text { Days } \\
\text { MED } \\
(5)\end{array}$ & $\begin{array}{c}\text { \# Fills } \\
(6)\end{array}$ & $\begin{array}{l}\text { Days } \\
\text { supply } \\
\text { (7) }\end{array}$ & $\begin{array}{c}\text { Days } \\
\text { MED } \\
(8)\end{array}$ & $\begin{array}{c}>90 \text { DS } \\
(9)\end{array}$ & $\begin{array}{c}>120 \text { Daily } \\
\text { MED } \\
(10)\end{array}$ & $\begin{array}{c}\geq 3 \\
\text { prescribers } \\
(11)\end{array}$ & $\begin{array}{c}\text { Opioid } \\
\text { overlap } \\
(12)\end{array}$ & $\begin{array}{l}\text { Concurrent } \\
\text { benzo. } \\
\text { (13) }\end{array}$ \\
\hline \multicolumn{14}{|c|}{ A. Main Estimates } \\
\hline Limits & $\begin{array}{c}0.048 \\
(0.023)\end{array}$ & $\begin{array}{c}0.037 \\
(0.019)\end{array}$ & $\begin{array}{r}-0.040 \\
(0.007)\end{array}$ & $\begin{array}{c}-0.453 \\
(0.135)\end{array}$ & $\begin{array}{c}0.606 \\
(1.570)\end{array}$ & $\begin{array}{c}0.012 \\
(0.015)\end{array}$ & $\begin{array}{c}-0.611 \\
(0.313)\end{array}$ & $\begin{array}{c}1.163 \\
(4.491)\end{array}$ & $\begin{array}{r}-0.059 \\
(0.113)\end{array}$ & $\begin{array}{c}0.001 \\
(0.010)\end{array}$ & $\begin{array}{c}0.152 \\
(0.178)\end{array}$ & $\begin{array}{c}-0.271 \\
(0.134)\end{array}$ & $\begin{array}{c}0.028 \\
(0.242)\end{array}$ \\
\hline PDMP & $\begin{array}{c}-0.029 \\
(0.013)\end{array}$ & $\begin{array}{c}-0.026 \\
(0.028)\end{array}$ & $\begin{array}{c}-0.012 \\
(0.007)\end{array}$ & $\begin{array}{c}-0.194 \\
(0.129)\end{array}$ & $\begin{array}{c}-0.671 \\
(1.720)\end{array}$ & $\begin{array}{c}0.005 \\
(0.009)\end{array}$ & $\begin{array}{c}-0.233 \\
(0.269)\end{array}$ & $\begin{array}{c}-0.595 \\
(6.289)\end{array}$ & $\begin{array}{c}-0.014 \\
(0.085)\end{array}$ & $\begin{array}{c}-0.004 \\
(0.013)\end{array}$ & $\begin{array}{c}0.109 \\
(0.090)\end{array}$ & $\begin{array}{c}-0.107 \\
(0.148)\end{array}$ & $\begin{array}{c}-0.404 \\
(0.217)\end{array}$ \\
\hline \multicolumn{14}{|c|}{ B. Tight initial prescription limits only } \\
\hline Limits & $\begin{array}{c}0.052 \\
(0.023)\end{array}$ & $\begin{array}{c}0.046 \\
(0.021)\end{array}$ & $\begin{array}{c}-0.039 \\
(0.007)\end{array}$ & $\begin{array}{c}-0.426 \\
(0.133)\end{array}$ & $\begin{array}{c}1.097 \\
(1.617)\end{array}$ & $\begin{array}{c}0.013 \\
(0.015)\end{array}$ & $\begin{array}{c}-0.533 \\
(0.311)\end{array}$ & $\begin{array}{c}2.461 \\
(4.921)\end{array}$ & $\begin{array}{c}-0.022 \\
(0.113)\end{array}$ & $\begin{array}{c}0.002 \\
(0.011)\end{array}$ & $\begin{array}{c}0.130 \\
(0.172)\end{array}$ & $\begin{array}{c}-0.230 \\
(0.137)\end{array}$ & $\begin{array}{c}0.094 \\
(0.245)\end{array}$ \\
\hline PDMP & $\begin{array}{c}-0.028 \\
(0.014)\end{array}$ & $\begin{array}{c}-0.027 \\
(0.030)\end{array}$ & $\begin{array}{c}-0.010 \\
(0.008)\end{array}$ & $\begin{array}{c}-0.184 \\
(0.142)\end{array}$ & $\begin{array}{c}-0.735 \\
(1.856)\end{array}$ & $\begin{array}{c}0.004 \\
(0.010)\end{array}$ & $\begin{array}{c}-0.242 \\
(0.293)\end{array}$ & $\begin{array}{c}-0.935 \\
(6.856)\end{array}$ & $\begin{array}{c}-0.034 \\
(0.090)\end{array}$ & $\begin{array}{c}-0.003 \\
(0.014)\end{array}$ & $\begin{array}{c}0.121 \\
(0.099)\end{array}$ & $\begin{array}{c}-0.098 \\
(0.165)\end{array}$ & $\begin{array}{c}-0.480 \\
(0.230)\end{array}$ \\
\hline \multicolumn{14}{|c|}{ C. Loose initial prescription limits } \\
\hline Limits & $\begin{array}{c}0.042 \\
(0.016)\end{array}$ & $\begin{array}{c}0.044 \\
(0.021)\end{array}$ & $\begin{array}{c}-0.019 \\
(0.014)\end{array}$ & $\begin{array}{c}-0.232 \\
(0.168)\end{array}$ & $\begin{array}{c}1.244 \\
(1.385)\end{array}$ & $\begin{array}{c}0.006 \\
(0.007)\end{array}$ & $\begin{array}{c}-0.274 \\
(0.269)\end{array}$ & $\begin{array}{c}3.903 \\
(4.920)\end{array}$ & $\begin{array}{r}-0.057 \\
(0.066)\end{array}$ & $\begin{array}{c}0.010 \\
(0.011)\end{array}$ & $\begin{array}{c}0.097 \\
(0.081)\end{array}$ & $\begin{array}{c}-0.028 \\
(0.149)\end{array}$ & $\begin{array}{r}-0.006 \\
(0.169)\end{array}$ \\
\hline PDMP & $\begin{array}{c}-0.029 \\
(0.013)\end{array}$ & $\begin{array}{c}-0.028 \\
(0.028)\end{array}$ & $\begin{array}{c}-0.014 \\
(0.008)\end{array}$ & $\begin{array}{c}-0.213 \\
(0.137)\end{array}$ & $\begin{array}{c}-0.793 \\
(1.780)\end{array}$ & $\begin{array}{c}0.005 \\
(0.010)\end{array}$ & $\begin{array}{c}-0.264 \\
(0.281)\end{array}$ & $\begin{array}{c}-1.069 \\
(6.438)\end{array}$ & $\begin{array}{c}-0.012 \\
(0.088)\end{array}$ & $\begin{array}{c}-0.005 \\
(0.013)\end{array}$ & $\begin{array}{c}0.113 \\
(0.100)\end{array}$ & $\begin{array}{c}-0.136 \\
(0.151)\end{array}$ & $\begin{array}{c}-0.399 \\
(0.214)\end{array}$ \\
\hline \multicolumn{14}{|c|}{ D. Alternative coding of must-access PDMPs } \\
\hline Limits & $\begin{array}{c}0.050 \\
(0.022)\end{array}$ & $\begin{array}{c}0.040 \\
(0.023)\end{array}$ & $\begin{array}{r}-0.040 \\
(0.007)\end{array}$ & $\begin{array}{c}-0.458 \\
(0.124)\end{array}$ & $\begin{array}{c}0.884 \\
(1.755)\end{array}$ & $\begin{array}{c}0.008 \\
(0.014)\end{array}$ & $\begin{array}{c}-0.658 \\
(0.292)\end{array}$ & $\begin{array}{c}1.312 \\
(5.896)\end{array}$ & $\begin{array}{c}-0.080 \\
(0.113)\end{array}$ & $\begin{array}{c}0.003 \\
(0.011)\end{array}$ & $\begin{array}{c}0.165 \\
(0.170)\end{array}$ & $\begin{array}{c}-0.321 \\
(0.129)\end{array}$ & $\begin{array}{c}0.084 \\
(0.234)\end{array}$ \\
\hline PDMP & $\begin{array}{c}-0.032 \\
(0.015)\end{array}$ & $\begin{array}{c}-0.031 \\
(0.036)\end{array}$ & $\begin{array}{c}-0.011 \\
(0.008)\end{array}$ & $\begin{array}{c}-0.177 \\
(0.139)\end{array}$ & $\begin{array}{c}-1.139 \\
(2.446)\end{array}$ & $\begin{array}{c}0.011 \\
(0.009)\end{array}$ & $\begin{array}{c}-0.139 \\
(0.283)\end{array}$ & $\begin{array}{c}-0.836 \\
(9.065)\end{array}$ & $\begin{array}{c}0.024 \\
(0.100)\end{array}$ & $\begin{array}{r}-0.007 \\
(0.017)\end{array}$ & $\begin{array}{c}0.081 \\
(0.107)\end{array}$ & $\begin{array}{c}-0.014 \\
(0.141)\end{array}$ & $\begin{array}{c}-0.486 \\
(0.249)\end{array}$ \\
\hline
\end{tabular}

Notes: "DS" stands for days supply, and "MED" is morphine equivalent doses. Hazard rate and extreme outcomes are multiplied by 100. Table reports estimates of the coefficients on indicators for "initial prescription limits" and "must access PDMPs", obtained from estimating OLS regressions of the indicated variables against policy indicators, state fixed effects, and month-year fixed effects. In Panel A we use our baseline coding of the policies, treating limits for 14 days or fewer as effective. In Panel B we code initial prescriptions only if they are for 7 days or fewer. In Panel C, we use a loose coding of initial prescription limits that treats all limits as effective. In Panel D we use an alternative coding of must-access PDMPs. Robust standard errors, clustered on state, in parentheses 


\section{Figure A.1: Event study results for intensive margin outcomes}
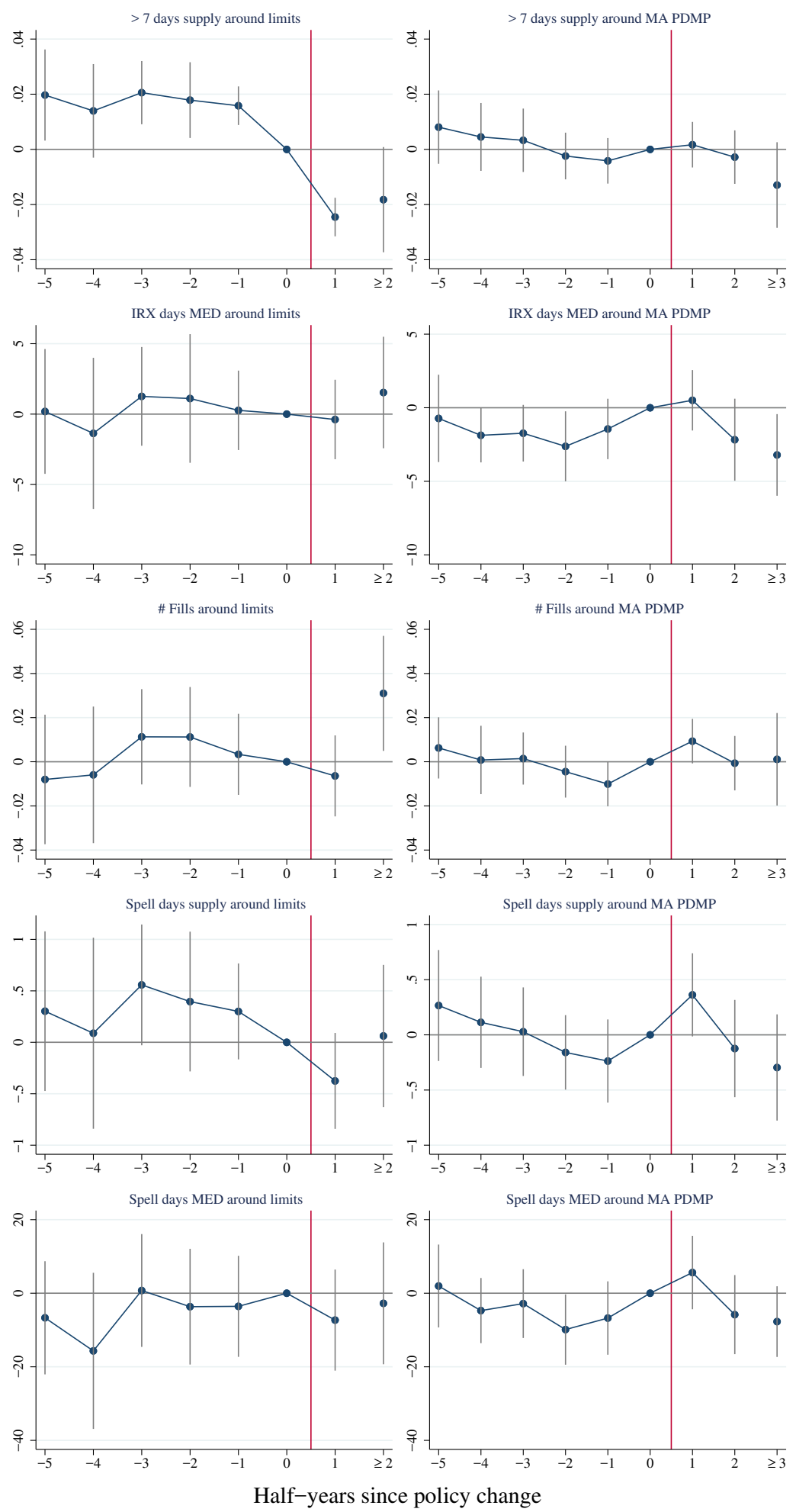

Notes: Figure shows the estimated coefficients on half-years since must-access PDMP enactment (in the left panels) and half-years since initial prescription limits enactment (in the right panels), obtained from estimating Equation 2 for the indicated outcomes. 
Figure A.2: Event study results for indicators of dangerous use
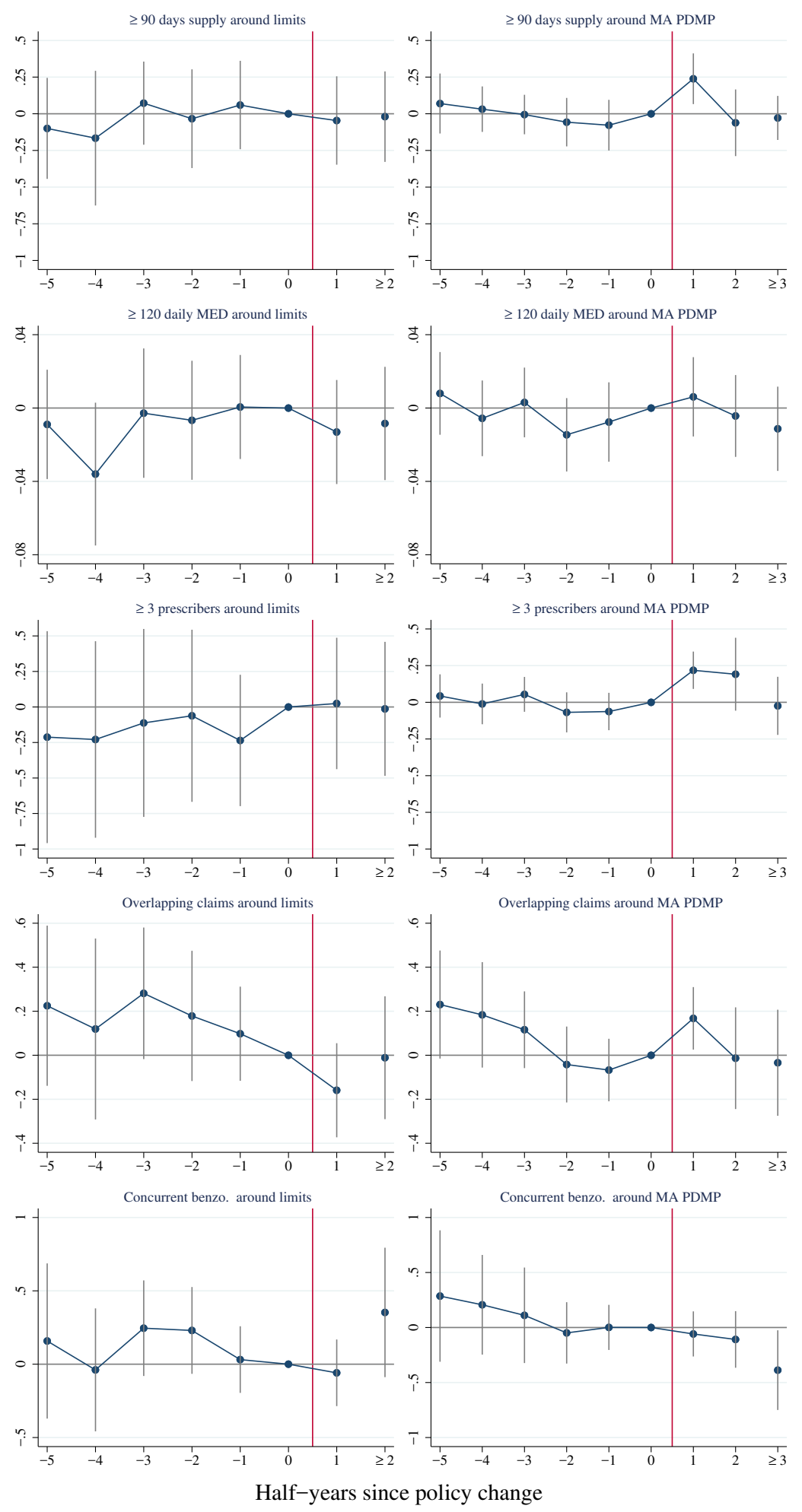

Notes: Figure shows the estimated coefficients on half-years since must-access PDMP enactment (in the left panels) and half-years since initial prescription limits enactment (in the right panels), obtained from estimating Equation 2 for the indicated outcomes. 
Figure A.3: Copay per days supply falls with days supply

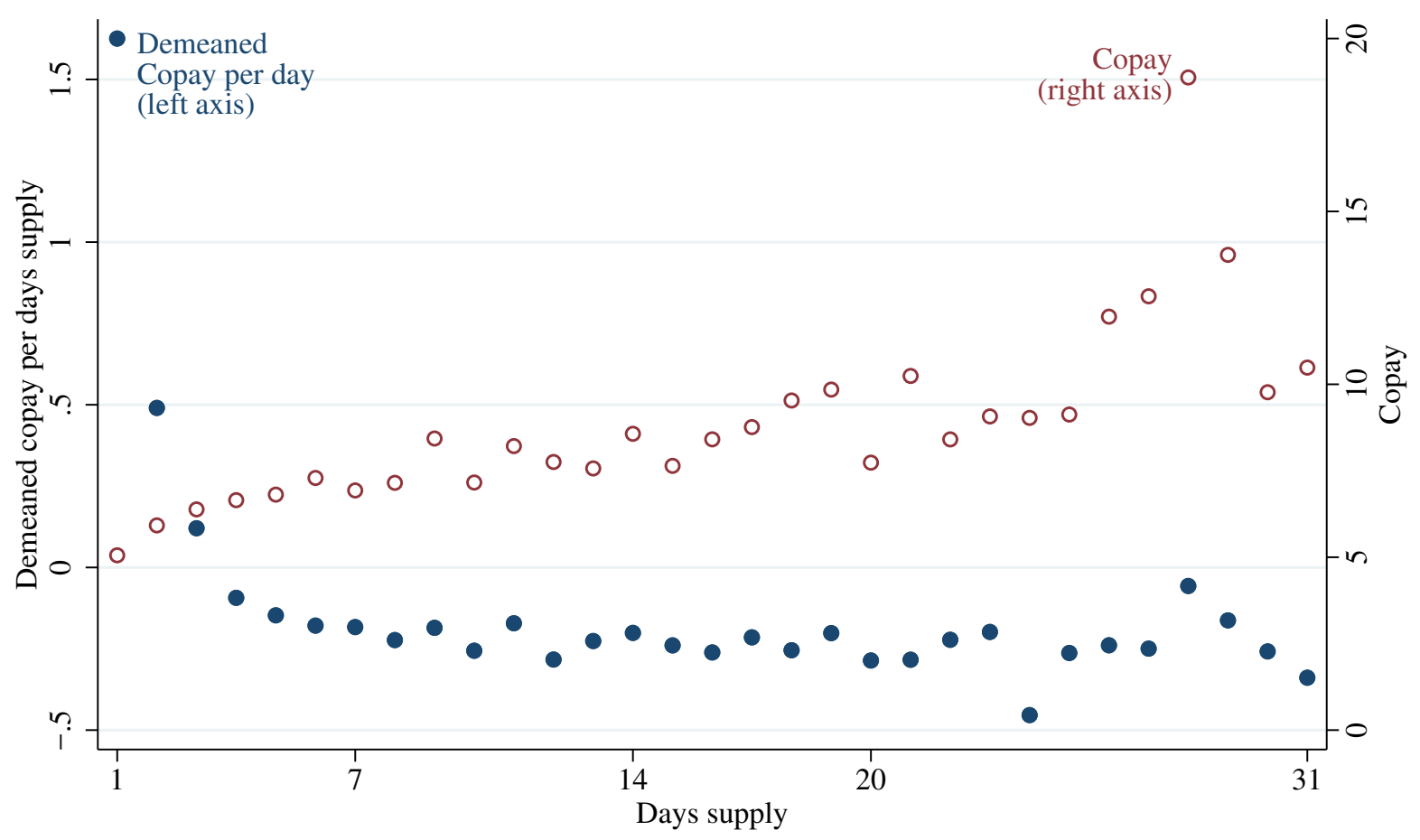

Notes: Figure shows the average copay per days supply (demeaned relative to the NDC-year average) as a function of days supply (left axis), and the average copay of prescribed drugs (right axis), among new opioid fills.. 